\title{
Necdin Plays a Role in the Serotonergic Modulation of the Mouse Respiratory Network: Implication for Prader-Willi Syndrome
}

\author{
Sébastien Zanella, ${ }^{1}$ Françoise Watrin, ${ }^{2}$ Saïda Mebarek, ${ }^{1,2}$ Fabienne Marly, ${ }^{2}$ Michel Roussel, ${ }^{3}$ Catherine Gire, ${ }^{4}$ \\ Gwenaëlle Diene, ${ }^{5}$ Maïté Tauber, ${ }^{5}$ Françoise Muscatelli, ${ }^{2 *}$ and Gérard Hilaire ${ }^{1 *}$ \\ ${ }^{1}$ Centre National de la Recherche Scientifique, Unité Mixte de Recherche 6231, Centre de Recherche en Neurobiologie et Neurophysiologie de Marseille, \\ Equipe Maturation, Plasticité, Physiologie Pathologie de la Respiration, Faculté Saint Jérôme, Case 362, 13397 Marseille Cedex 20, France, ${ }^{2}$ Centre National \\ de la Recherche Scientifique, Unité Mixte de Recherche 6216, Institut de Biologie du Développement de Marseille, Luminy, 13288 Marseille Cedex 9, France, \\ ${ }^{3}$ Service de Neurophysiologie Clinique and ${ }^{4}$ Service de Pédiatrie, Centre Hostitalier Universitaire Nord-Chemin des Bourrely, 13015 Marseille, France, and \\ ${ }^{5}$ Hôpital des Enfants, 73431026 Toulouse Cedex 3, France
}

Prader-Willi syndrome is a neurogenetic disease resulting from the absence of paternal expression of several imprinted genes, including NECDIN. Prader-Willi children and adults have severe breathing defects with irregular rhythm, frequent sleep apneas, and blunted respiratory regulations. For the first time, we show that Prader-Willi infants have sleep apneas already present at birth. In parallel, in wild-type and Necdin-deficient mice, we studied the respiratory system with in vivo plethysmography, in vitro electrophysiology, and pharmacology. Because serotonin is known to contribute to CNS development and to affect maturation and function of the brainstem respiratory network, we also investigated the serotonergic system with HPLC, immunohistochemistry, Rabies virus tracing approaches, and primary culture experiments. We report first that Necdin-deficiency in mice induces central respiratory deficits reminiscent of Prader-Willi syndrome (irregular rhythm, frequent apneas, and blunted respiratory regulations), second that Necdin is expressed by medullary serotonergic neurons, and third that Necdin deficiency alters the serotonergic metabolism, the morphology of serotonin vesicles in medullary serotonergic neurons but not the number of these cells. We also show that Necdin deficiency in neonatal mice alters the serotonergic modulation of the respiratory rhythm generator. Thus, we propose that the lack of Necdin expression induces perinatal serotonergic alterations that affect the maturation and function of the respiratory network, inducing breathing deficits in mice and probably in Prader-Willi patients.

Key words: Prader-Willi syndrome; Necdin; respiratory system; serotonin; infants; mice

\section{Introduction}

Prader-Willi syndrome (PWS) is a complex and evolutive neurogenetic disease. At birth, severe neonatal hypotonia results in failure-to-thrive. Hyperphagia leads to serious obesity, which develops during childhood (Goldstone, 2004). PWS patients present many other clinical features also (hypogonadism, skin picking, daytime sleepiness, cognitive impairments) and important behavioral problems (Goldstone, 2004). PWS is also associ-

\footnotetext{
Received March 30, 2007; revised Dec. 20, 2007; accepted Dec. 24, 2007.

This work was supported by European Community Grant 512136 (P.W.S.), a Centre National de la Recherche Scientifique postdoctoral fellowship (S.M.), the Université de la Méditerranée, the Université Paul Cézanne, and Groupe d'Intérêt Scientifique France Grant GISMR0209. We thank Patrice Coulon and Michelle Bevengut for Rabies virus experiments, Magali Barthelemy-Requin for HPLC experiments, and Robert Kelly for English corrections. We are grateful to all of the Prader-Willi patients and families and to Drs. Michel Tiberge and Anne Broué, who contributed to the clinical data analysis for this study. We acknowledge the contribution of Fabrice Wallois with contro infants.

*F.M. and G.H. contributed equally to this work

Correspondence should be addressed to Gérard Hilaire, Centre National de la Recherche Scientifique, Unité Mixte de Recherche 6231, Equipe Maturation, Plasticité, Physilogie et Pathologie de la Respiration, Faculté Saint Jérôme, Case 362, 13397 Marseille Cedex 20, France. E-mail: gerard.hilaire@univ-cezanne.fr.

DOI:10.1523/JNEUROSCI.4334-07.2008

Copyright $\odot 2008$ Society for Neuroscience $\quad$ 0270-6474/08/281745-11\$15.00/0
}

ated with breathing deficits, rhythm instability, severe sleep apneas, and blunted respiratory responses to hypoxia and hypercapnia that may develop before obesity (Nixon and Brouillette, 2002). PWS breathing deficits are risk factors for an early, unexpected sudden death (Schrander-Stumpel et al., 2004; Nagai et al., 2005); however, the physiological cause is still unclear.

The human paternal NECDIN gene is deleted or inactivated in PWS (Jay et al., 1997), which is an imprinting disease, involving at least two genes from the 15q11-q13 chromosomal region (Goldstone, 2004). Necdin paternal-deficient mice [referred to as $N d n$-KO (knock-out)] have been generated, showing postnatal respiratory distress leading to lethality in a fraction of pups in the first postnatal $48 \mathrm{~h}$ (Gerard et al., 1999; Muscatelli et al., 2000). Necdin has been shown to act as an anti-apoptotic factor during the wave of naturally occurring cell death (Andrieu et al., 2003) and to affect neuronal migration, axonal extension, arborization, and fasciculation later in development (Lee et al., 2005; Pagliardini et al., 2005). Thus, Necdin deficiency in Ndn-KO mice, and probably PWS patients, may affect neural networks maturation and function. Surviving $N d n$-KO mice present phenotypic characteristics such as a high level of scraping, a particular cognitive 
profile (Muscatelli et al., 2000), sensory-motor defects, and an altered pain threshold (Andrieu et al., 2006), which reveal striking parallels with some of the phenotypic manifestations in PWS patients. The Ndn-KO model is consequently a good model for specific symptoms of PWS.

Here, for the first time, we report frequent central sleep apneas from birth in PWS neonates and, in parallel, respiratory instability, frequent apneas, and blunted respiratory regulations in surviving $N d n$-KO neonates, similar to those reported in PWS. Because the metabolism of serotonin (5-HT) may be altered in PWS patients (Akefeldt et al., 1998; Akefeldt and Mansson, 1998) and because 5-HT contributes to CNS development (Gaspar et al., 2003), respiratory network maturation (Bou-Flores et al., 2000), and modulation of the central respiratory activity (Hilaire and Duron, 1999; Bou-Flores et al., 2000), the question arises whether breathing deficits of $\mathrm{Ndn}$ - $\mathrm{KO}$ and PWS originate from 5-HT alterations. We show that Necdin is expressed in 5-HT neurons. Interestingly, in the absence of Necdin, we reveal an increased content of 5-HT in the medulla, alterations of 5-HT vesicles in medullary fibers but no changes in the number of 5-HT medullary neurons, and an altered 5-HT modulation of the respiratory rhythm generator. Our data support a primary role of NECDIN deficiency in breathing deficits of PWS neonates and suggest that alterations in 5-HT system play a role in those breathing deficits.

\section{Materials and Methods}

Human infants breathing recordings. No infants have been recorded especially for this study. Analyses were performed on previously stored data files (French Reference Center for PWS, Toulouse, France; Centre Hospitalier Universitaire Nord, Marseilles, France; Explorations Fonctionnelles du Système Nerveux, CHU Amiens, France) originating from infants from birth to 50 months of age, who were previously hospitalized for medical reasons (hypotonia, low weight, respiratory deficits, parent anxiety, etc.). They were genotyped for PWS diagnostic and had routine polysomnographic recordings from 9:00 P.M. to 6:00 A.M., with abdominal-thoracic captors (chest respiratory movements), mouthnasal flux captor (upper airway flux), electrocardiogram, and electroencephalography. Nonobese, non-PWS infants of matched ages and weights with no respiratory deficits were used as controls. During sleep periods, an Apnea Index (AI) was defined as the number of central apneas more than duration of two missing respiratory cycles $(>6 \mathrm{~s})$ per hour (total arrest of both upper airway flux and chest movements $>6 \mathrm{~s}$ ). No sleep obstructive apneas were detected (abolition of upper airway flux but persistence of chest respiratory movements).

Animals breeding and genotyping. Experiments were performed in keeping with the European guidelines for the care and use of laboratory animals (Council Directive 86/6009/EEC) of mice at embryonic day 16.5 (E16.5), postnatal day $2(\mathrm{P} 2)$, and $\mathrm{P} 30 . N d n$ is an imprinted gene that is expressed from the paternal allele and silenced on the maternal allele. Heterozygous males carrying an $\mathrm{Ndn}$-deleted allele were bred to wildtype (WT) females $(\mathrm{C} 57 \mathrm{BL} / 6 \mathrm{~J}$ background) to generate WT $(+\mathrm{m} /+\mathrm{p})$ and heterozygotes animals $(+\mathrm{m} /-\mathrm{p})$ with the paternal allele deleted, referred to in the text as $N d n-\mathrm{KO}$, used for analyses. Genotyping was performed as described previously (Muscatelli et al., 2000).

In vivo recordings of mouse breathing patterns. As reported previously (Viemari et al., 2004, 2005), breathing was recorded from unrestrained, unanesthetized P2 and P30 mice in a constant air flow whole-body plethysmograph (EMKA Technologies, Paris, France). Animal chambers were maintained at $32 \pm 0.5^{\circ} \mathrm{C}(25 \mathrm{ml})$ and $25 \pm 0.5^{\circ} \mathrm{C}(200 \mathrm{ml})$ for P2 and $\mathrm{P} 30$ mice, respectively. We measured the mean respiratory frequency in cycles per minute $\left(\mathrm{c} \mathrm{min}^{-1}\right)$ and $\mathrm{AI}$ only during quiet periods when mice were apparently sleeping. In neonatal mice, similar to PWS neonates, we defined AI as the number of apneas more than duration of two missing respiratory cycles $(>1 \mathrm{~s})$ per hour. AI was also calculated for apneas of longer duration ( $>4$ missing cycles; i.e., $>2 \mathrm{~s}$ ). In adult mice where the duration of respiratory cycles was very short $(\sim 330 \mathrm{~ms})$, AI was defined as the number of apneas $>3$ cycles $(>1 \mathrm{~s})$ per hour, but AI was also calculated for longer apneas ( $>6$ cycles; i.e., $>2 \mathrm{~s}$ ).

To check the ventilation responses to hypoxia and hypercapnia, we first recorded control ventilation (100\%) during a $60 \mathrm{~min}$ period under air, and then replaced air with a hypoxic $\left(10 \% \mathrm{O}_{2}-90 \% \mathrm{~N}_{2}\right)$ or hypercapnic $\left(4 \% \mathrm{CO}_{2}\right.$ in air) mixture for $5 \mathrm{~min}$. Changes occurring during the two last minutes were expressed as percentage of control. Routinely, breathing of four mice was simultaneously recorded in the four-chambers plethysmograph, allowing comparison between WT and $\mathrm{Ndn}$-KO littermates placed in identical conditions.

In vitro recordings in "en bloc" medullary preparations. As reported previously (Viemari et al., 2004; Zanella et al., 2006, 2007), P2 mice were decerebrated; the medulla and the cervical spinal cord were dissected and placed ventral sides up in a $2 \mathrm{ml}$ chamber perfused $\left(4 \mathrm{ml} \mathrm{min}^{-1}\right)$ with artificial CSF (aCSF) (129 mM NaCl, $3.35 \mathrm{~mm} \mathrm{KCl,} 1.26 \mathrm{~mm} \mathrm{CaCl}_{2}, 1.15$ $\mathrm{mm} \mathrm{MgCl}, 21 \mathrm{~mm} \mathrm{NaHCO}_{3}, 0.58 \mathrm{~mm} \mathrm{NaH}_{2} \mathrm{PO}_{4}, 30 \mathrm{~mm}$ Glucose) bubbled with carbogen $\left(\mathrm{pH} 7.4\right.$, at $\left.27^{\circ} \mathrm{C}\right)$. The $\mathrm{C} 4$ phrenic nerve activity was recorded with suction electrode to measure the phrenic burst frequency (PBF) expressed in $\mathrm{c} \mathrm{min}^{-1}$. In some cases, the respiratory discharges of the hypoglossal and the $\mathrm{C} 4$ phrenic nerves were simultaneously recorded. AI was defined as the number of phrenic pauses more than duration of two respiratory cycles $(>10 \mathrm{~s})$ per hour. In control periods $>200$ consecutive cycles, the cycle period variability was measured with the irregularity score (IS) defined as IS $=100^{\star} \operatorname{ABS}\left(P_{\mathrm{n}}-P_{\mathrm{n}-1}\right) / P_{\mathrm{n}-1}$, with $P$ being the period of the $n$th respiratory cycle (Viemari et al., 2005). To test the response of the respiratory rhythm generator (RRG) to applications of either exogenous serotonin (5-HT) or specific 5-HT receptor (5-HT-R) agonists [8-hydroxy-2-(di- $n$-propylamino)tetralin (8OHDPAT), 4-iodo-2,5-dimethoxyamphetamine (DOI), and methyl-5(2-thienylmethoxy)-1 $\mathrm{H}$-indole-3-ethanamine hydrochloride (BW 723C86) for $5-\mathrm{HT}_{1 \mathrm{~A}}-\mathrm{R}, 5-\mathrm{HT}_{2 \mathrm{~A}}-\mathrm{R}$, and $5-\mathrm{HT}_{2 \mathrm{~B}}-\mathrm{R}$, respectively] or hypoxia, the normal aCSF was changed to modified aCSF for $5 \mathrm{~min}$ (aCSF containing drugs or nonoxygenated aCSF bubbled with $95 \% \mathrm{~N}_{2} / 5 \%$ $\mathrm{CO}_{2}, \mathrm{pH} 7.4$, at $\left.27^{\circ} \mathrm{C}\right)$. Changes were expressed as percentage of control $\mathrm{PBF}$ (one trial per preparation) and were averaged minute per minute from different preparations. Routinely, two preparations were simultaneously recorded in the same in vitro chamber, allowing comparison of pairs of WT and $N d n-\mathrm{KO}$ littermates. All drugs were purchased from Sigma (St. Louis, MO).

Biochemical analysis. As reported previously (Viemari et al., 2005), neonates were cold anesthetized and adults were killed with a lethal pentobarbitone injection $\left(300 \mathrm{mg} . \mathrm{kg}^{-1}\right.$, i.p.). Then, the brains were rapidly dissected out, and the medullas were weighed and kept at $-80^{\circ} \mathrm{C}$ until biochemical analysis. The endogenous concentrations of 5-HT and the main 5-HT metabolite 5-hydroxyindole-3-acetic acid (5HIAA) were measured using HPLC (UVK Laboratory, Paris, France) coupled with electrochemical detection.

Rabies virus tracing experiments. Rabies virus (RV) infects neurons and only neurons (no glial cells) and transynaptically propagates in a retrograde manner through synaptically connected neurons of a network. Therefore, diaphragmatic inoculation of RV (the Challenge Virus Standard strain of RV; Laboratoire de Virologie Moléculaire et Structurale, Centre National de la Recherche Scientifique, Gif sur Yvette, France) have been used to infect and label neurons from the brainstem respiratory network, as reported previously in adult mice (Gaytan et al., 2002) and neonatal mice (Hilaire et al., 2004; Viemari et al., 2004; Hilaire, 2006; Zanella et al., 2006; Bevengut et al., 2008). As stated by Morcuende et al. (2002), RV "is the most valuable, particularly for studying motor networks, because after its injection into muscles or nerves, it is taken up exclusively by motoneurons, without uptake by sensory or sympathetic neurons." In neonatal mice, after RV diaphragmatic inoculation (Bevengut et al., 2008) (Fig. S1, available at www.jneurosci.org as supplemental material), RV successively infects, step by step, phrenic motoneurons $(24-30 \mathrm{~h})$ (Fig. S1 A, available at www.jneurosci.org as supplemental material), medullary premotoneurons $(30-36 \mathrm{~h})$, second-order interneurons of the ventral respiratory group, Bötzinger group, and pre-Bötzinger Complex (36-42 h) (Fig. S1B,C, available at www. jneurosci.org as supplemental material), third-order interneurons in the raphe (42-48 h) (Fig. S1 D, available at www.jneurosci.org as supple- 
mental material), nTS, A5, and A6 areas, etc. While time elapses, RV further propagates in the brainstem and upper CNS structures, but some areas remain devoid of infected neurons, even $48-54 \mathrm{~h}$ after RV injection, such as the VII, X, and XII motor nuclei (Fig. S1E, F, available at www.jneurosci.org as supplemental material) and the medullary A1/C1 and $\mathrm{A} 2 / \mathrm{C} 2$ catecholaminergic neurons (data not shown) (Hilaire et al., 2004; Hilaire, 2006; Zanella et al., 2006).

The present study was focused on the RV-infected neurons from medullary raphe and respiratory related areas at $42-48 \mathrm{~h}$ after RV inoculation in the diaphragm at P0. All procedures were conducted in an enclosure physically separated from the other parts of the laboratory (guidelines for Biosafety Level 2 laboratory practices). After cold anesthesia of P0 neonates, the skin, the superficial muscles, and the fat laying above the 10th to 11th intercostal space were dissected to allow insertion of the needle of a $10 \mu \mathrm{l}$ Hamilton syringe within the diaphragm and injection of $1 \mu \mathrm{l}$ of $\mathrm{RV}$ suspension $\left(4 \times 10^{9}\right.$ plaque forming units $\left./ \mathrm{ml}\right)$ over $1 \mathrm{~min}$. The whole procedure did not last $>15 \mathrm{~min}$. All neonates recovered after warming. They were given back to their mother and killed $42-48 \mathrm{~h}$ later. The $\mathrm{RV}$-infected neurons were identified in brainstem slices with a monoclonal mouse anti-RV (produced by P. Coulon in the laboratory).

Immunohistofluorescence. E16.5 embryo heads, P2 whole brains, or brainstems from WT and $\mathrm{Ndn}$-KO littermates pairs were dissected, fixed in $4 \%$ paraformaldehyde/PBS, cryoprotected in PBS/20\% sucrose, embedded in OCT (Tissue-Tek; Sakura, Tokyo, Japan) and sectioned at 20 $\mu \mathrm{m}$. For experiments involving cell counting, one of five sections was arranged serially on slides to obtain five complete series of every brain. Sections were blocked in PBS/0.1\% Triton X-100/7\% heat-inactivated goat or donkey serum for $1 \mathrm{~h}$. They were then incubated overnight at $4^{\circ} \mathrm{C}$ with the following primary antibodies: polyclonal rabbit anti-Necdin (1/1000; Upstate Biotechnology, Lake Placid, NY), polyclonal rabbit anti-tyrosine hydroxylase (TH) (1/500; Institut J. Boy, Reims, France), polyclonal goat anti-5-HT (1/500; Immunostar, Hudson, WI) and monoclonal mouse anti-challenge virus standard Rabies virus (1/1000). Immunolabeling was detected with the following secondary antibodies: donkey anti-rabbit Alexa Fluor 488 (1/200; Invitrogen, Eugene, OR), donkey anti-goat Alexa Fluor 546 (1/200; Invitrogen), donkey antirabbit tetramethylrhodamine isothiocyanate (1/200; Interchim, Montlucon, France), donkey anti-goat Alexa Fluor 488 (FluoProbes, 1/500; Interchim), donkey anti-mouse AMCA (1/200; Jackson ImmunoResearch, West Grove, PA), goat anti-rabbit Alexa Fluor 546 (1/500; Invitrogen), and goat anti-mouse Alexa Fluor 488 (FluoProbes, 1/500; Interchim). Slides were mounted in Vectashield mounting medium with $4^{\prime}, 6^{\prime}$ diamidino-2-phenylindole (Vector Laboratories, Burlingame, CA). Images were acquired with an Axiocam MRm digital camera (Zeiss, Thornwood, NY) on an Axioplan2 Imaging microscope (Zeiss) with an Apotome module (Zeiss), using AxioVision 4.4.1.0 software (Zeiss). Images were assembled with the Adobe Photoshop (Adobe Systems, San Jose, CA) CS2 software. The methods for the in situ detection of Necdin mRNA are reported in supplemental Figure S2 (available at www.jneurosci.org as supplemental material).

Primary serum-free cultures of 5-HT raphe neurons and immunocytochemical labeling. Cultures of medullary raphe neurons were prepared from neonatal (P2) mice from four mutants and four WT animals, following a protocol for serum-free cultures (Brewer, 1995), which was modified and adapted to raphe neurons (Lautenschlager et al., 2000). The dissection included neurons from all three medullary raphe nuclei: raphe obscurus, raphe magnus, and raphe pallidus. Defined tissue pieces were rinsed twice with PBS, incubated in trypsin/EDTA $(0.05 / 0.02 \%$ $\mathrm{w} / \mathrm{vol}$ in PBS) for $15 \mathrm{~min}$ at $37^{\circ} \mathrm{C}$, washed twice (first with PBS and then with dissociation medium: MEM supplemented with $10 \%$ fetal calf serum, $100 \mathrm{IE}$ insulin/L, $0.5 \mathrm{~mm}$ glutamine, $100 \mathrm{U} / \mathrm{ml}$ penicillin/streptomycin, $44 \mathrm{~mm}$ glucose and $10 \mathrm{~mm}$ HEPES buffer), dissociated mechanically by fire-polished Pasteur pipettes, centrifuged at $210 \times g$ for $2 \mathrm{~min}$ at $21^{\circ} \mathrm{C}$, redissociated in starter medium (serum-free neurobasal medium supplemented with $\mathrm{B} 27,0.5 \mathrm{~mm}$ glutamine, $100 \mathrm{U} / \mathrm{ml}$ penicillin/streptomycin, and $25 \mu \mathrm{m}$ glutamate), counted and plated in four-well plates at a density of 100,000 cells $/ \mathrm{cm}^{2}$. Plates were pretreated with poly-L- ornithine $(0.5 \%$ in $\mathrm{PBS})$ for $2 \mathrm{~h}$ at $37^{\circ} \mathrm{C}$, followed by incubation with laminin overnight at $37^{\circ} \mathrm{C}$. Cultures were kept $4 \mathrm{~d}\left(37^{\circ} \mathrm{C}, 5 \% \mathrm{CO}_{2}\right)$, the first $2 \mathrm{~d}$ in a medium with glutamate and the following $2 \mathrm{~d}$ in a medium without glutamate. Cells were then washed twice with PBS and fixed in $4 \%$ paraformaldehyde/PBS for $15 \mathrm{~min}$ at room temperature. After three rinses with PBS, the cells were incubated with a blocking solution containing $5 \%$ heat-inactivated goat serum, $2 \%$ bovine serum albumine dissolved in PBS supplemented with $0.5 \%$ Triton X-100 for $1 \mathrm{~h}$ at room temperature. Incubation with polyclonal rabbit anti 5-HT diluted (1/500) in blocking solution was performed overnight at $4^{\circ} \mathrm{C}$. Immunolabeling was detected with the secondary antibody goat anti-rabbit Alexa Fluor 488 (1/500; Invitrogen). For each culture, 200 neurons were analyzed for the 5-HT vesicles data.

Statistical analysis. All data were analyzed using SigmaStat software (SPSS, Erkrath, Germany). The first step of the analysis was to verify the assumptions of normality and homoscedasticity of the samples. All values given are mean \pm SEM, unless stated otherwise. Mean values (breathing frequency and ventilation changes, PBF, IS, and AI values, bioamines concentrations, number and size of vesicles in 5-HT fibers, etc.) were compared between WT and Ndn-KO mice by Student's $t$ test. Changes in $\mathrm{PBF}$ induced by modified aCSF and differences between genotypes were analyzed by a two-way ANOVA with one criteria repeated (minute) followed by Dunnett's tests to compare the control frequency to the frequency under modified aCSF during each minute. All tests were made on absolute values. Statistical significance was taken at $p \leq 0.05$.

\section{Results}

\section{Central sleep apneas are frequent in PWS neonates}

During sleep, polysomnography of 10 PWS infants (median, 16 months of age; range, 1-50) who were not obese (body mass index, median $16 \mathrm{~kg} / \mathrm{m}^{2}$; range, 15.5-18.9) revealed an irregular breathing interrupted by frequent sleep apneas that were central from origin (i.e., nonobstructive apneas), because they occurred with simultaneous cessation of both nasal flux and chest movements. In seven of 10 PWS infants, counting sleep apneas more than two missing respiratory cycles $(>6 \mathrm{~s})$ led to a pathological AI (median, 2.1 apneas per hour; range, 1.1-16). However, the remaining three PWS infants had very few apneas $>6 \mathrm{~s}$ and normal AI (median, 0.12). The recommended limit for normal AI in infants is $<1$ (Uliel et al., 2004). In 10 control infants of matched ages and weights, we counted very few sleep apneas more than two missing respiratory cycles $(>6 \mathrm{~s})$, leading to AI values significantly lower than those of PWS infants (median, 0.37; range, $0-1.2 ; p<0.001$ ). Thus, PWS infants suffer from central sleep apneas. Among those PWS infants, one was diagnosed at $2 \mathrm{~d}$ of age (P2). He already had very frequent sleep apneas $>6 \mathrm{~s}(\mathrm{AI}, 11)$ (Fig. 1A), whereas three control neonates had 10-fold less frequent apneas. Three weeks later, sleep apneas remained frequent in this PWS neonate (AI, 16) but not in controls (AI, 0). Thus, most $(70 \%)$ but not all PWS infants suffer from central sleep apneas in the class of 1 to 50 months of age. We did not observe a correlation between occurrence of sleep apneas and the type of genetic mutation (deletion, disomy) (supplemental Table 1, available at www.jneurosci.org as supplemental material).

\section{Central apneas are frequent in $\mathrm{Ndn}$-KO neonates and adults}

Because NDN is involved in PWS and Necdin deficiency affects the prenatal maturation of the respiratory network in mice (Ren et al., 2003; Pagliardini et al., 2005), we examined whether Necdin deficiency in mice induced neonatal breathing deficits resembling those of PWS neonates. We then compared breathing of $\mathrm{WT}$ and $N d n$-KO mice (Fig. $1 B$ ). In unrestrained, unanesthetized neonatal mice, plethysmography at P2 showed that breathing frequency was similar in $\mathrm{Ndn}$-KO $\left(n=12 ; 128 \pm 16 \mathrm{c} \mathrm{min}^{-1}\right)$ and WT $\left(n=10 ; 116 \pm 4 \mathrm{c} \mathrm{min}^{-1}\right)$ during quiet periods of recording when mice apparently slept. However, apneas $>2$ respiratory cycles $(>1 \mathrm{~s})$ were approximately threefold more fre- 
quent in $N d n$-KO $(\mathrm{AI}, 367 \pm 14)$ than WT (AI, $136 \pm 37)$ mice. A similar difference was observed with longer apneas. Apneas $>4$ cycles $(>2 \mathrm{~s})$ were 10 -fold more frequent in Ndn-KO (AI, $164 \pm 57$ ) than WT (AI, $15 \pm 8)$ mice $(p<0.01)$. Although two $N d n-\mathrm{KO}$ had $>300$ apneas $>2$ s per hour, two $N d n$-KO mice breathed normally. As breathing appeared more irregular in $N d n$-KO than in WT mice, we further examined the variability of the respiratory cycle duration using the IS (Viemari et al., 2005), which was twofold larger in $N d n-\mathrm{KO}(47 \pm 3)$ than in WT $(27 \pm 1)$ neonates $(p<0.001)$.

In unrestrained, unanesthetized adult mice (P30), plethysmography showed that most $N d n-\mathrm{KO}$ mice retained an altered breathing pattern during quiet periods when they apparently slept (Fig. 1C). No significant differences in mean respiratory frequency, tidal volume, and minute ventilation were observed between genotypes. However, apneas were significantly more frequent in $N d n-\mathrm{KO}(n=11$; AI, $225 \pm$ 102 and $105 \pm 43$ for apneas $>3$ and 6 cycles; i.e., $>1$ s and $>2$ s, respectively) than in WT $(n=12$; AI, $7 \pm 3$ and $1 \pm 1$ for apneas $>3$ and 6 cycles; i.e., $>1$ s and $>2$ s) adult mice. Although two Ndn-KO mice had $>150$ apneas $>6$ cycles per hour, two $N d n-\mathrm{KO}$ mice had normal breathing. In addition, cycle duration was significantly more variable in $N d n$-KO (IS, $55 \pm 11$ ) than in WT (IS, $12 \pm 3 ; p<0.01)$ mice.

Submitting adult mice to hypoxia $(10 \%$ of $\mathrm{O}_{2}$ in $\mathrm{N}_{2}, 5 \mathrm{~min} ; 11 \mathrm{Ndn}$-KO, $12 \mathrm{WT}$ ) or hypercapnia ( $4 \%$ of $\mathrm{CO}_{2}$ in air, $5 \mathrm{~min} ; 8$ $N d n-\mathrm{KO}, 10 \mathrm{WT})$ increased minute ventilation in both genotypes. However, the mean increase in minute ventilation was $40 \%$ less in $\mathrm{Ndn}$-KO compared with WT mice $(p<0.01)$.

Therefore, Necdin deficiency induces breathing deficits in neonatal and adult mice similar to those reported in PWS patients: irregular rhythm, frequent apneas, and blunted respiratory regulations. Noticeably, the expression of these breathing alterations is variable in mice, although they have an identical C57BL/6J genetic background.

Respiratory deficits of $\mathrm{Ndn}$-KO neonates have a central component

To examine whether breathing deficits of $\mathrm{Ndn}$-KO neonates originated from central or peripheral alterations, we compared the rhythmic phrenic bursts produced by the isolated RRG in en bloc medullary preparations from $N d n-\mathrm{KO}(n=10)$ and WT $(n=$ 10) neonates at P2 (Fig. $2 A$ ). In both genotypes, the phrenic bursts had a similar

\section{A - Human neonates (P2)} PWS
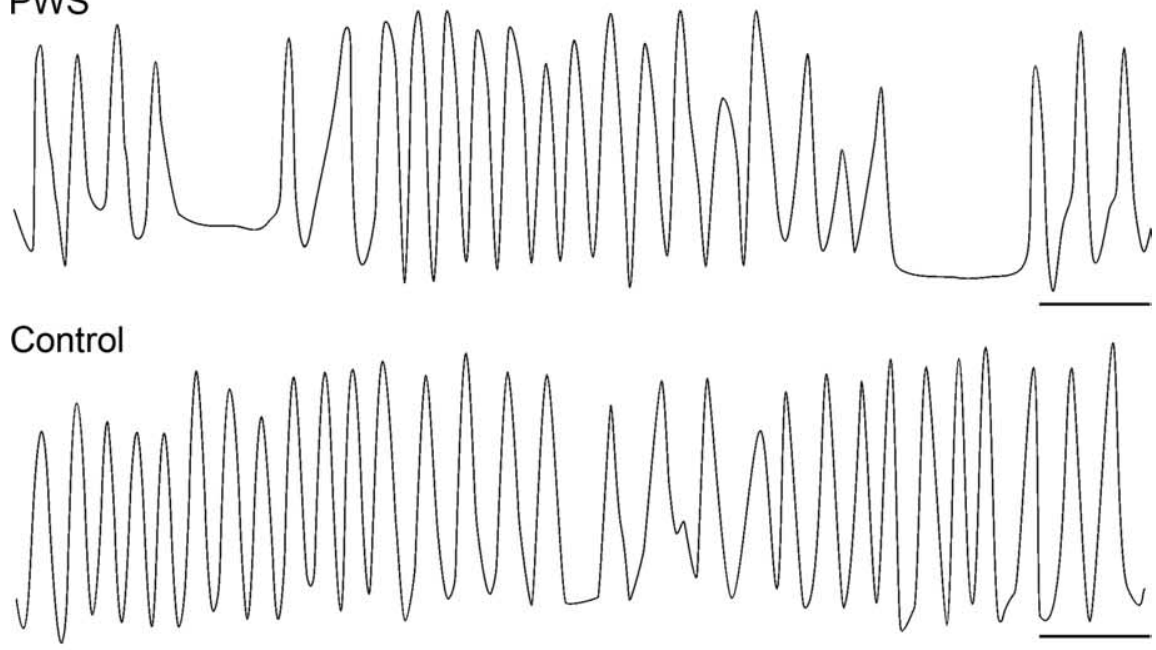

\section{B - Mouse neonates (P2)}

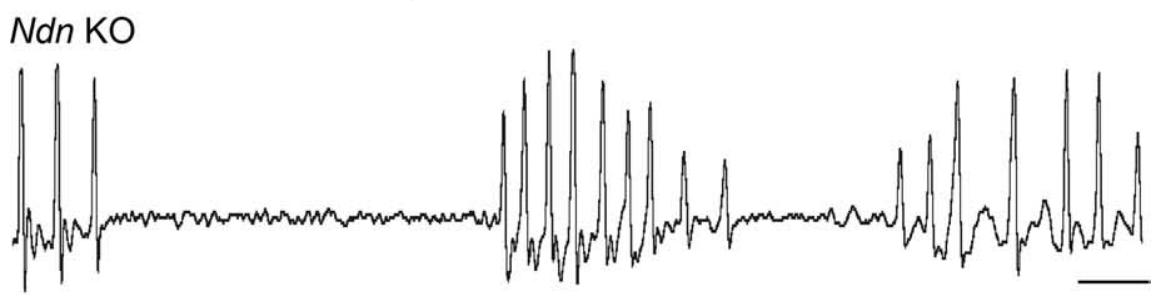

WT

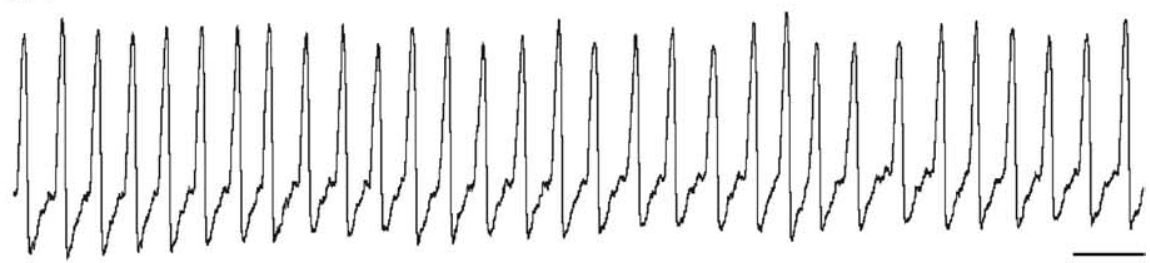

C - Mouse adults (P30)

$\mathrm{Ndn} \mathrm{KO}$

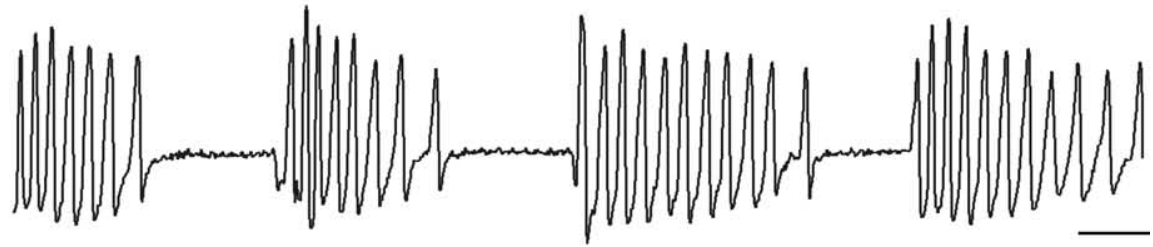

WT

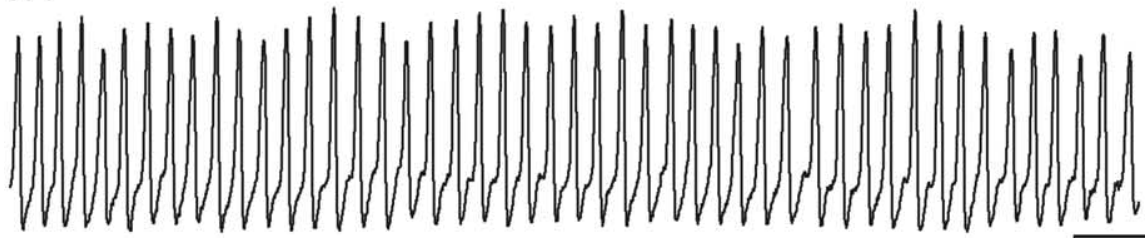

Figure 1. Breathing deficits of PWS patients and Ndn-KO mice. $A$, Human neonates: breathing recordings during sleep periods in PWS and control P2 neonates (top and bottom traces, respectively) reveal frequent sleep apneas in PWS patient but not in control (time scale, 10 s). B, Mouse neonates: breathing recordings in unrestrained, unanesthetized Ndn-K0 and WT P2 mice (top and bottom traces, respectively) reveal frequent apneas in quiet, probably sleeping, $N d n$-KO but not in WT mice (time scale, $1 \mathrm{~s}$ ). C, Mouse adults: same as above but for unrestrained, unanesthetized Ndn-KO and WT P30 mice (top and bottom traces, respectively) (time scale, $1 \mathrm{~s}$ ). 
A

Ndn KO (P2)

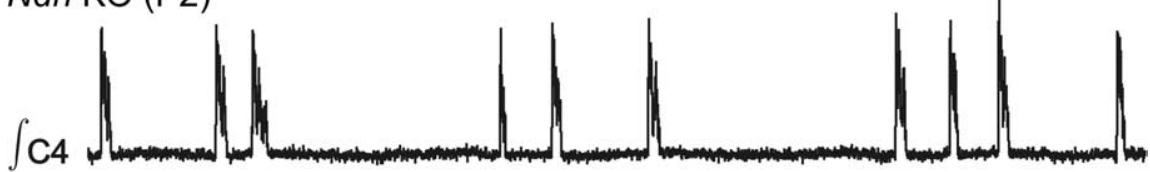

WT (P2)

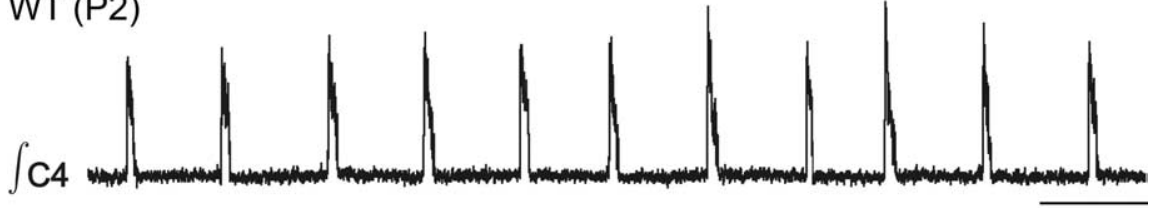

B

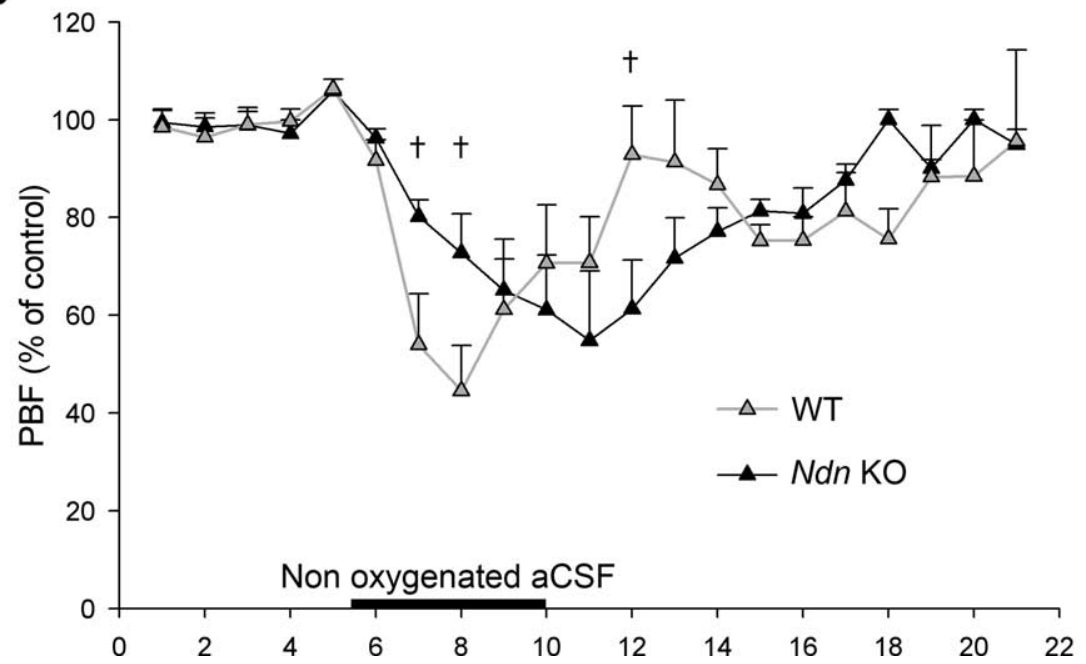

Figure 2. Altered in vitro respiratory activity and altered response to central hypoxia of en bloc medullary preparations from $\mathrm{Ndn}$-KO neonates. $\boldsymbol{A}$, Recordings of rhythmic phrenic bursts (integrate) produced by en bloc medullary preparations from Ndn-K0 and WT P2 mice (top and bottom traces, respectively) reveal frequent respiratory arrests $>10 \mathrm{~s}$ in Ndn-K0 but not in WT preparations (time scale, $10 \mathrm{~s}$ ). This difference was even observed during simultaneous recordings of Ndn-KO and WT preparations. $\boldsymbol{B}$, Curves show mean changes (and SEM) in PBF (expressed as a percentage of control every minute) from nine $\mathrm{Ndn}-\mathrm{KO}$ and nine WT preparations (filled and open triangles, respectively) when the normal oxygenated aCSF (first 5 min; control 100\%) is replaced by a nonoxygenated aCSF for 5 min (horizontal bar). ${ }^{* *} p<0.001 ;{ }^{\dagger} p<0.05$.

shape, and the mean of the PBF was similar $(\mathrm{PBF}, 12.1 \pm 0.6 \mathrm{c}$ $\left.\min ^{-1}\right)$. However, respiratory arrests $>2$ cycles $(>10 \mathrm{~s})$ were threefold times more frequent in $N d n$-KO (AI, $52 \pm 7$ ) than in $\mathrm{WT}(\mathrm{AI}, 16 \pm 3 ; p<0.001)$ preparations. In addition, mean IS was larger in $N d n-\mathrm{KO}$ (IS, 96.3 \pm 3.7 ) than in WT (IS, 66.2 \pm 1.9 ; $p<0.001)$ preparations. Simultaneous recordings of the respiratory bursts produced on both phrenic and hypoglossal nerves in $N d n$-KO and WT preparations did not reveal obvious anomalies of hypoglossal versus phrenic discharges in $N d n-\mathrm{KO}(n=5)$. Thus, the totally deafferented RRG of $N d n$-KO neonates functions but produces a variable rhythm, interrupted by frequent pauses.

We subsequently examined the effect of central hypoxia on the RRG activity of $\mathrm{P} 2$ preparations during the $5 \mathrm{~min}$ period when the normal oxygenated aCSF is replaced by a nonoxygenated aCSF (Fig. $2 B$ ). In WT preparations $(n=9)$, as shown previously (Blanchi et al., 2003), the PBF was depressed during the first 3 min of hypoxia; then the PBF slightly increased during the last $2 \mathrm{~min}$, although it remained significantly depressed until the end of the hypoxic challenge. In $N d n$-KO preparations $(n=$ 9), central hypoxia also depressed the PBF, but the time course of the depression was slower. The PBF was significantly less depressed after $3 \mathrm{~min}$ of hypoxia in $\mathrm{Ndn}$-KO than in WT prepara- tions, and thereafter the PBF continued to decrease during the last 2 min of hypoxia in $\mathrm{Ndn}$-KO preparations, whereas it increased in WT preparations.

\section{The RRG of $N d n-\mathrm{KO}$ neonates abnormally responds to exogenous 5-HT}

We analyzed the PBF changes induced by application of aCSF containing different drugs to WT and Ndn-KO medullary preparations at $\mathrm{P} 2(25 \mu \mathrm{M} ; 5 \mathrm{~min}) .5-\mathrm{HT}$ is known to induce three different effects: it increases the PBF, decreases the phrenic burst amplitude, and induces a tonic discharge via the activation of medullary $5-\mathrm{HT}_{1 \mathrm{~A}}-\mathrm{R}$, spinal $5-\mathrm{HT}_{1 \mathrm{~B}}-\mathrm{R}$, and spinal $5-\mathrm{HT}_{2 \mathrm{~A}}-\mathrm{R}$, respectively (Hilaire and Duron, 1999; Bou-Flores et al., 2000). In nine WT preparations (Fig. $3 A$ ), the PBF increased in the first minute of 5-HT application and reached $150 \pm 10 \%$ of the control over the whole $5 \mathrm{~min}$ period (Fig. 3D) $(p<0.05)$. 5-HT also depressed the phrenic burst amplitude (activation of spinal $\left.5-\mathrm{HT}_{1 \mathrm{~B}}-\mathrm{R}\right)$ and induced tonic discharges (activation of spinal 5- $\mathrm{HT}_{2 \mathrm{~A}}-\mathrm{R}$ ). In all $N d n$-KO preparations $(n=9), 5-\mathrm{HT}$ application systematically induced the $5-\mathrm{HT}_{1 \mathrm{~B}}-\mathrm{R}$ depression of phrenic burst amplitude and the $5-\mathrm{HT}_{2 \mathrm{~A}}-\mathrm{R}$ tonic discharges but, surprisingly, never increased the PBF (Fig. 3B). 5-HT had no significant effects on the PBF in the first minute of application and thereafter depressed it to $73 \pm 3 \%$ of the control (Fig. 3D) $(p<0.01)$. Interestingly, respiratory arrests $>10 \mathrm{~s}$ that occurred under normal aCSF were abolished by 5 -HT (Fig. 3C1,C2), leading to rhythm stabilization, with a $50 \%$ significant decrease of IS $(p<0.01)$. Applying 8-OHDPAT to medullary preparations (four WT and three $N d n-\mathrm{KO}$ ), a $5-\mathrm{HT}_{1 \mathrm{~A}}-\mathrm{R}$ agonist known to mimic the 5-HT facilitatory effects on the RRG (Hilaire and Duron, 1999; Bou-Flores et al., 2000), increased the PBF by $47 \pm 10 \%$ in both genotypes, without stabilizing the $\mathrm{Ndn}$-KO rhythm. Applying the 5- $\mathrm{HT}_{2 \mathrm{~A}}-\mathrm{R}$ agonist DOI (six WT and three $N d n-\mathrm{KO}$ ) and the 5- $\mathrm{HT}_{2 \mathrm{~B}}-\mathrm{R}$ agonist BW $723 \mathrm{C} 86$ (three WT and three $N d n-\mathrm{KO}$ ) slightly increased the PBF by $\sim 10 \%$ in both genotypes, without stabilizing the $N d n-\mathrm{KO}$ rhythm. Thus, 5-HT stabilized the irregular rhythm of $N d n-\mathrm{KO}$ through not yet identified mechanisms.

\section{Ndn-KO neonates have altered 5-HT systems}

We hypothesized that the 5-HT medullary system was altered in $\mathrm{Ndn}$-KO neonates and measured the 5-HT and 5HIAA concentrations in the medulla of $N d n-\mathrm{KO}(n=28)$ and WT $(n=18)$ neonates at P2 with HPLC. The mean 5-HT concentrations were significantly larger in $\mathrm{Ndn}$-KO $(8.8 \pm 1.2 \mu \mathrm{mol} / \mathrm{g})$ than WT by $52 \%(5.8 \pm 0.7 \mu \mathrm{mol} / \mathrm{g} ; p<0.05)$, whereas the 5HIAA concentrations were similar $(21.6 \pm 2.4$ and $21.8 \pm 2.2 \mu \mathrm{mol} / \mathrm{g})$. This led to a ratio 5-HT/5HIAA that was 53\% larger in $N d n-\mathrm{KO}$ than WT $(p<0.001)$, revealing altered 5-HT metabolism in $\mathrm{Ndn}$-KO neonates. In P30 mice, HPLC showed that 5-HT and 5HIAA con- 
centrations tended to be larger by $15-20 \%$ in $N d n$-KO mice (11.9 \pm 0.7 and $6.2 \pm 0.5$ $\mu \mathrm{mol} / \mathrm{g}$, for 5 -HT and 5HIAA; $n=5)$ than in WT mice $(10.3 \pm 0.5$ and $5.2 \pm 0.3 \mu \mathrm{mol} / \mathrm{g}$, for 5 -HT and 5HIAA; $n=7)$. However, the differences between both genotypes at P30 were not statistically significant at $p<0.05$ ( $p=0.09$ for both 5-HT and 5HIAA).

\section{Necdin is expressed by medullary}

\section{5-HT neurons}

From early developmental stages (E12.5), Necdin was found expressed in the medulla. At P2, Necdin expression was detected at high levels in all the medullary raphe nuclei (raphe obscurus, raphe pallidus, raphe magnus) and lateral 5-HT (Fig. 4) areas. In addition, Necdin was highly expressed in pontine structures anterior to the medulla such as the locus ceruleus and the dorsal tegmentum, as well as in medullary structures such as the solitary nucleus, area postrema, dorsal motor nucleus of vagus, and hypoglossal nucleus (Fig. S2, available at www.jneurosci.org as supplemental material). Colabeling experiments at E16.5 and P2 confirmed Necdin expression in 5-HT-positive neurons from the medullary raphe nuclei (Figs. 5, 6A-D). Virtually all 5-HT-positive neurons of both areas express Necdin; this was later confirmed using primary cell culture. Although Necdin transcript was detected in neurons of the rostral ventrolateral medulla (RVLM), Necdin protein was detected in fewer cells (Fig. S3, available at www. jneurosci.org as supplemental material). Interestingly, Necdin transcript was not found in the RVLM neurons that express the neurokinin 1 receptor in the pre-Bötzinger complex region (Fig. S3H, available at www.jneurosci.org as supplemental material) (Smith et al., 1991; Rekling and Feldman, 1998), nor in those of the parafacial respiratory group (pFRG) that are located just below the VII motor nucleus and may also contribute to respiratory rhythmogenesis (Onimaru and Homma, 2003) (Fig S2, available at www.jneurosci.org as supplemental material). Thus, this expression pattern does not favor a primary role of Necdin in the intrinsic mechanisms of respiratory rhythmogenesis.

\section{Necdin is expressed by 5-HT neurons} connected to the respiratory network We then investigated a functional link between Necdin-positive cells, 5-HT raphe neurons, and the respiratory network. We inoculated RV in the diaphragm of WT neonates and analyzed its retrograde propagation from phrenic motoneurons to the medullary respiratory network (Gaytan et al., 2002; Hilaire et al., 2004; Viemari et al., 2004; Hilaire, 2006; Zanella et al., 2006; Bevengut et al., 2008). RV infected, step by step, phrenic motoneurons, their medullary drivers, and second- and third-order interneurons in the respira-

Ndn KO (P2)
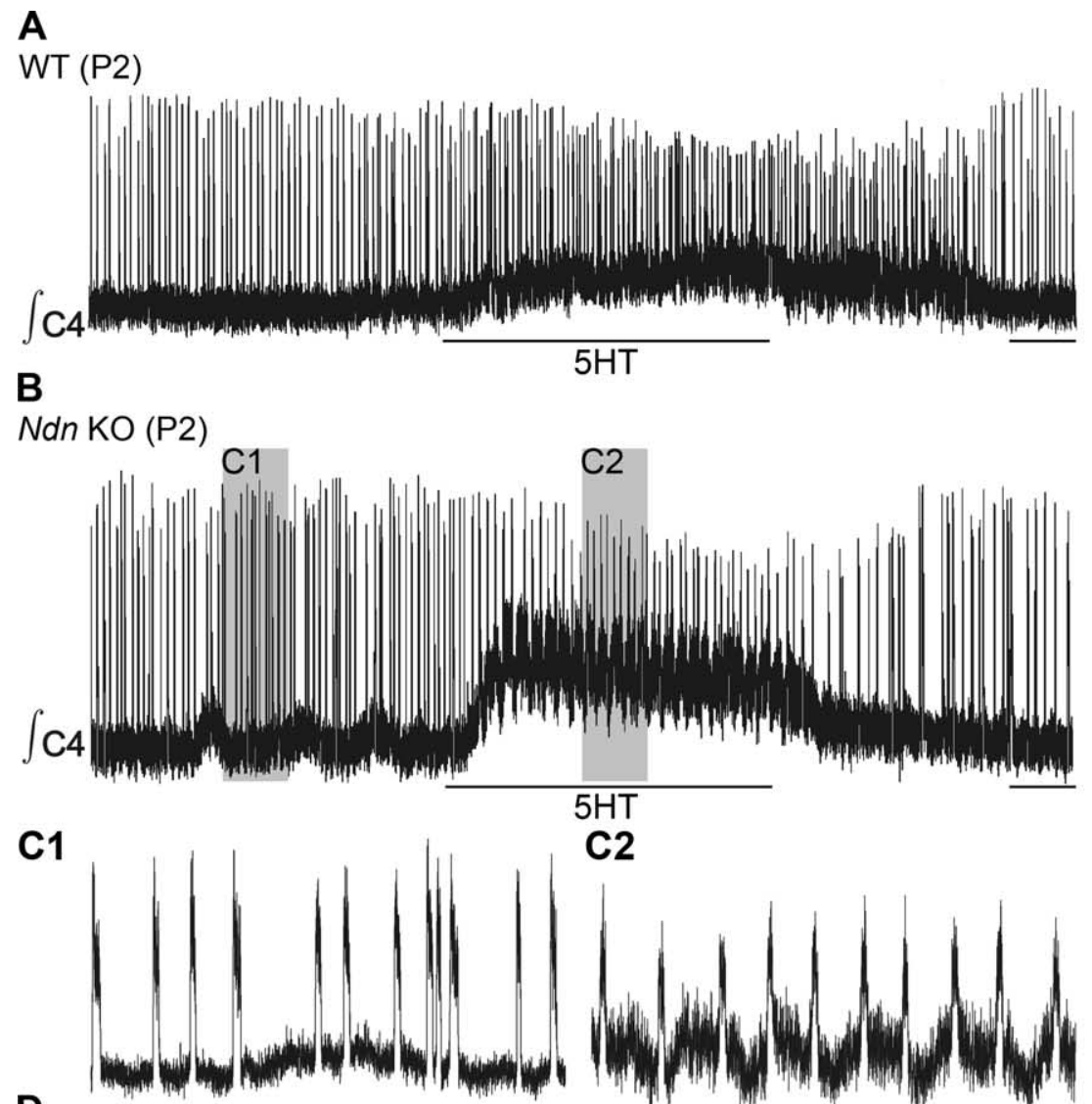

C2

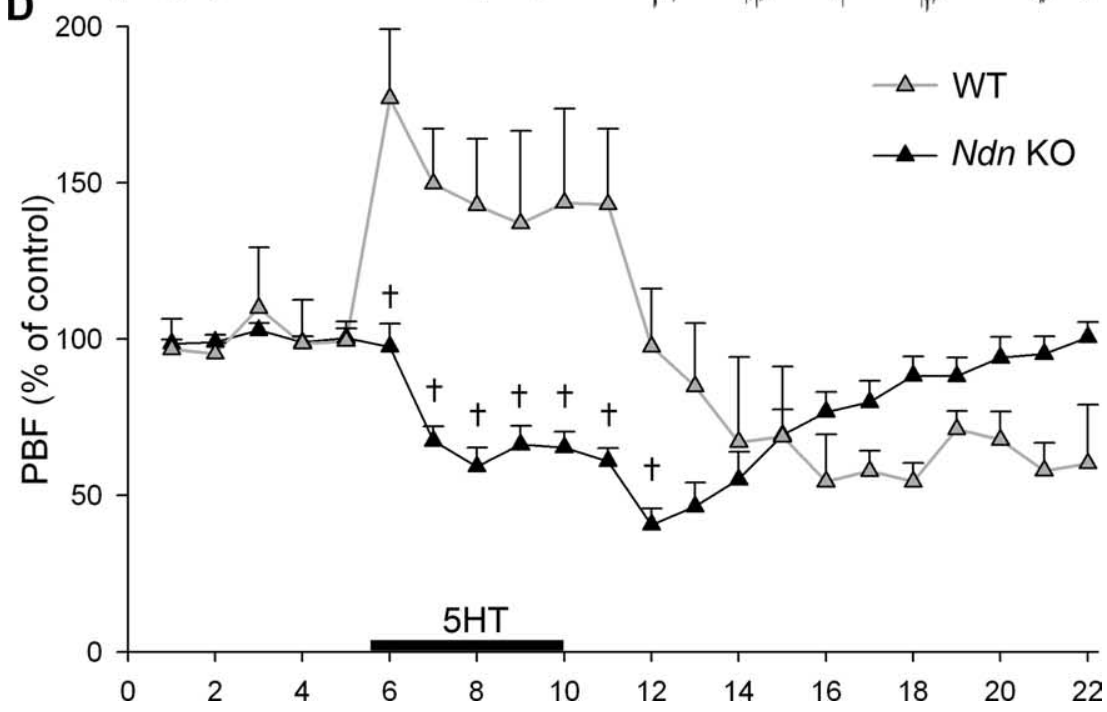

Figure 3. Altered 5-HT effects on the in vitro respiratory activity produced in en bloc medullary preparations from Ndn-KO neonates. $A, B$, Rhythmic phrenic bursts (integrate) recorded in two en bloc medullary preparations from WT $(A)$ and $N d n-K 0(B)$ P2 neonates superfused with normal aCSF and aCSF containing 5-HT (25 $\mu \mathrm{m}, 5 \mathrm{~min}$; horizontal bar). Note that 5-HT application decreased the phrenic burst amplitude and induced a tonic discharge in both preparations but had opposite effects on the phrenic burst frequency: facilitation in WT but reduction in Ndn-KO preparations (time scale, $60 \mathrm{~s}) . \mathbf{C 1}, \mathbf{C 2}$, Enlargements of the $1 \mathrm{~min}$ recordings shown in the gray areas of $\boldsymbol{B}$ under control aCSF (C1) and under aCSF containing 5-HT ( $(2)$; note the apnea $>10$ sin $\boldsymbol{C 1}$ and their disappearance under 5-HT in C2.D, Curves show the mean changes (and SEM) in the PBF (expressed in percentage of control every minute) from nine $\mathrm{Ndn}$-KO and nine WT preparations (filled and open triangles, respectively) when the normal aCSF (first $5 \mathrm{~min}$; control 100\%) is replaced by an aCSF containing 5 -HT (25 $\mu \mathrm{M}, 5 \mathrm{~min}$; horizontal bar). ${ }^{\dagger} p<0.05$. Note that 5 -HT increased the mean frequency in WT but decreased it in Ndn-KO mice.

tory related areas, etc. At $42-48 \mathrm{~h}$ after inoculation, a high density of infected neurons was found in raphe nuclei (Fig. S1 D, available at www.jneurosci.org as supplemental material). As reported previously (Bevengut et al., 2008), the raphe infection originates 

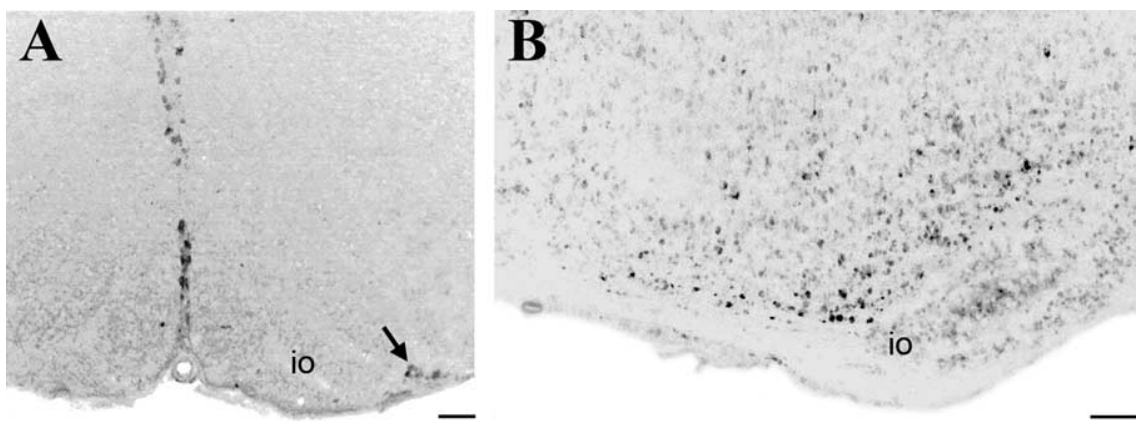

Figure 4. Necdin-expressing neurons in 5-HT areas of WT neonates. Transverse (left) and sagittal (right) medullary sections show Necdinexpressing neurons located in both medial and lateral (black arrow) 5-HT areas of WT P2 neonates. Scale bar, $100 \mu \mathrm{m}$. io, Inferior olive.
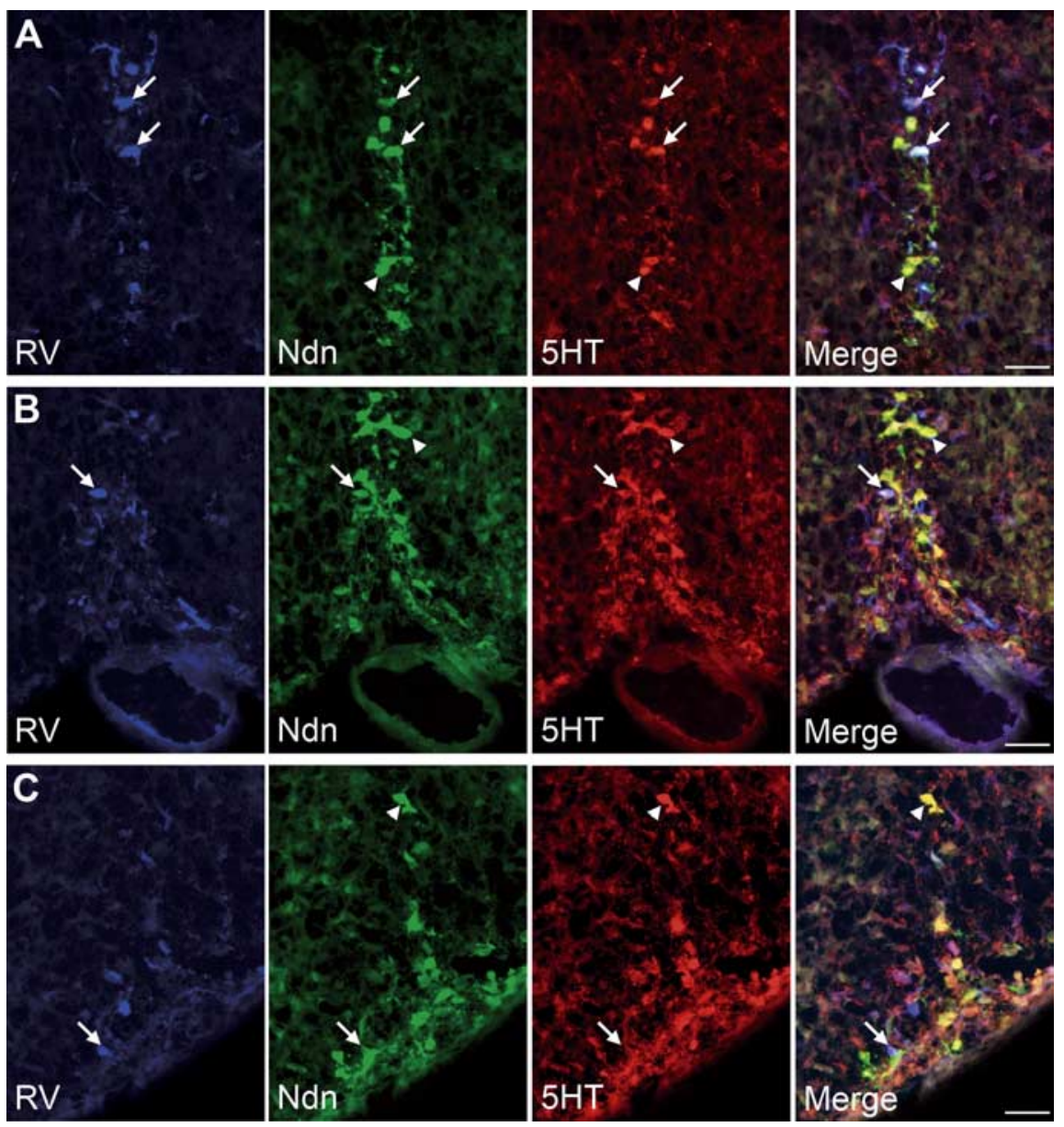

Figure 5. Medullary 5-HT neurons that express Necdin are synaptically connected to the respiratory network. RV is known to infect neurons, but not glia cells, and to propagate within chain of synaptically connected neurons in a retrograde manner. As reported previously (Bevengut et al., 2008), RV inoculation in the diaphragm of WT neonates allows identifying medullary respiratory neurons that are implicated in the control of the diaphragm (Fig. S1, available at www.jneurosci.org as supplemental material). RV successively infects phrenic motoneurons (postinoculation delay $24-30 \mathrm{~h}$ ), premotoneurons (30-36 h), and medullary interneurons from the ventral respiratory group, the Bötzinger complex, and the pre-Bötzinger complex ( $36-42 \mathrm{~h}$ ). At 42-48 h, a massive, bilateral RV infection of medullary 5 -HT neurons develops, consistently with synaptic projections from raphe to previously infected respiratory neurons. $\boldsymbol{A}-\boldsymbol{C}$, At this stage of RV infection, we performed a triple immunostaining against RV (blue), Necdin protein (green), and 5-HT (red) (from left to right; far right, merge) in five WT neonates that were RV inoculated at P0. Note that most5-HT neurons expressed Necdin (some are shown by arrowheads) and that some raphe neurons that expressed both 5-HT and Necdin were also RV infected (arrows). This was similarly observed in sections (20 $\mu \mathrm{m})$ from the medial raphe obscurus $(\boldsymbol{A})$, the medial raphe pallidus $(\boldsymbol{B})$, and the lateral group (C). Scale bar, $50 \mu \mathrm{m}$.

from two different synaptic pathways. First, at $30-36 \mathrm{~h}, \mathrm{RV}$ infects a few raphe obscurus neurons, ipsilateral to the inoculation site, through direct projections from raphe to phrenic motoneurons. Second, at $42-48 \mathrm{~h}$, a late, bilateral, and massive infection occurs in raphe obscurus, pallidus, and 5-HT lateral neurons. This reflects propagation through polysynaptic pathways, including projections from raphe to previously infected respiratory neurons (not especially the RRG), even if other pathways cannot be excluded.

Then, five WT neonates were killed 42-48 $\mathrm{h}$ after diaphragmatic inoculation at $\mathrm{P} 0$ and, at this postinoculation delay, we performed a triple immunostaining against 5-HT, Necdin, and RV proteins (Fig. 5AC). First, we confirmed that most of the medullary 5-HT neurons coexpressed Nec$\operatorname{din}(>95 \%)$. Second, we noted that most of the medullary 5-HT neurons that were RV infected (and probably participated in the 5-HT modulation of the respiratory network), coexpressed Necdin (89\%). The RV-Necdin-5-HT expressing neurons were similarly found within raphe obscurus (Fig. $5 A$ ), raphe pallidus (Fig. $5 B$ ), and lateral 5-HT groups (Fig. $5 C$ ). In this view, Necdin deficiency might affect these neurons and therefore the 5-HT modulation they exert on the respiratory network. Third, we did not observe a Necdin expression in $149 \mathrm{RV}$ infected neurons located within the preBötzinger complex areas of three different neonates.

\section{How does Necdin alter the 5-HT system} and trigger respiratory deficiency at birth?

First, we performed an immunohistochemical study of the medulla at P2 to label neurons that contained 5-HT or expressed the catecholaminergic synthesis enzyme tyrosine hydroxylase. Counting medullary neurons in three pairs of $\mathrm{Ndn}$ - $\mathrm{KO}$ and WT littermates did not reveal significant differences between both genotypes for 5-HTcontaining neurons $(661 \pm 85$ and $641 \pm$ 82 in 5-HT medial areas and $199 \pm 77$ and $217 \pm 44$ in 5-HT lateral areas for $\mathrm{Ndn}$-KO and WT, respectively) and for THexpressing neurons $(310 \pm 23$ and $304 \pm 8$ $\mathrm{A} 1 / \mathrm{C} 1$ neurons for $\mathrm{Ndn}-\mathrm{KO}$ and WT; $224 \pm 24$ and $227 \pm 29 \mathrm{~A} 2 / \mathrm{C} 2$ neurons for $N d n-\mathrm{KO}$ and WT). In addition, counting hypoglossal motoneurons did not reveal differences between WT and $N d n-K O$.

Second, we looked at the profile of the 5-HT innervation in WT and $\mathrm{Ndn}$-KO embryos and neonates. Abnormal projections of 5-HT fibers toward both the rostral CNS and the RVLM have been reported previously in Ndn-KO (Lee et al., 2005; Pagliardini et al., 2005). In addition, we noted differences in the morphology of 5-HT vesicles from medullary fibers in sections performed at the level of the pre-Bötzinger complex of WT and $N d n$-KO mice (Fig. 6, G and $H, E$ and F, and $I$ and $J$ for P2 neonates, E16.5 embryos, and P30 adults, respectively). 

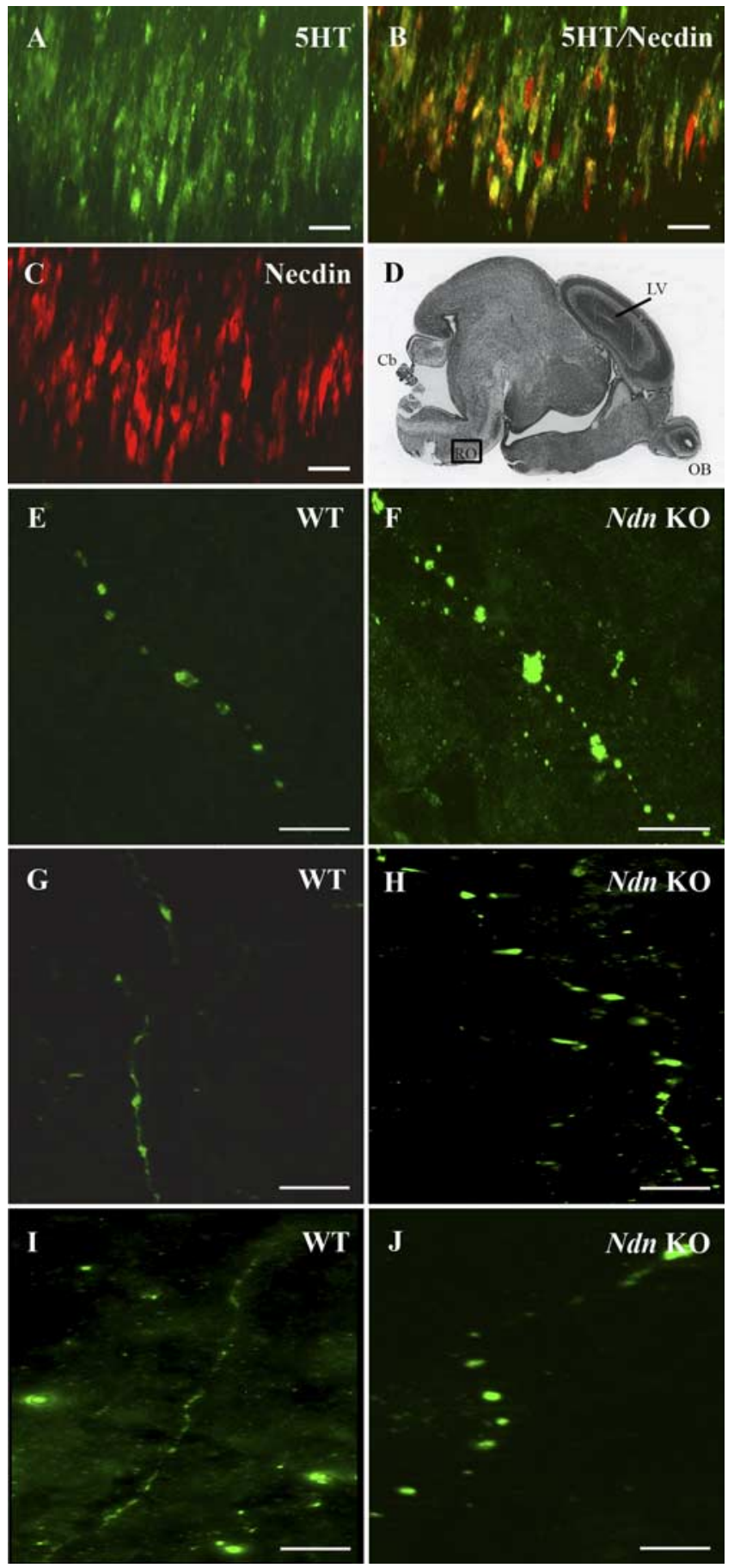

Figure 6. Abnormal 5 -HT vesicles in the ventral medulla of $N d n-K 0$ embryos, neonates, and adults. $\boldsymbol{A}-\boldsymbol{D}, 5-\mathrm{HT}$ (green, $\boldsymbol{A}$ ), Necdin (red, $\boldsymbol{C}$, and both (B) immunostaining on WT medulla sagittal sections of an Ndn-K0 embryo at E16.5. Note that Necdin is expressed in most 5-HT neurons of the medial raphe obscurus (R0; $\boldsymbol{D}) . \boldsymbol{E}-\boldsymbol{I}, 5-\mathrm{HT}$ (green) immunostaining on WT ( $\boldsymbol{E}, \boldsymbol{G}$, $\boldsymbol{I})$ and $N d n-K O(F, H, J)$ medullary fibers of E16.5 embryos $(\boldsymbol{E}, \boldsymbol{F}), \mathrm{P} 2$ neonates $(\boldsymbol{G}, \boldsymbol{H})$, and $\mathrm{P} 30$ adults $(I, J)$. At all studied ages, 5 -HT fibers in Ndn-KO mutant mice display irregularly distributed and enlarged 5 -HT vesicles. Scale bar, $10 \mu \mathrm{m}$.

In $N d n$-KO neonates, medullary 5-HT fibers frequently displayed irregularly distributed, large and swollen 5-HT vesicles (Fig. $6 \mathrm{H}$ ). Such 5 -HT vesicles were also frequent in $\mathrm{Ndn}$-KO embryos at E16.5 (Fig. $6 \mathrm{~F}$ ) and in $\mathrm{Ndn}$-KO adults at P30 (Fig. $6 \mathrm{~J}$ ).

Third, to allow the quantitative comparison between genotypes, we then performed primary cultures of raphe neurons from P2 neonates. In raphe cultures from WT, we detected Nec- din as vesicles in cellular bodies and dendrites in nearly all 5-HT neurons, 5-HT being expressed in apparently different vesicles (Fig. $7 A, B$ ). In raphe cultures from $N d n$-KO, we also observed 5-HT vesicles, but they appeared more frequent and larger (Fig. $7 D-G)$, resembling those observed in vivo. Counting large 5-HT vesicles (surface, $>0.5 \mu \mathrm{m}^{2}$ ) in 200 neurons cultured from WT and $N d n-\mathrm{KO}$ raphe revealed they were $\sim 10$-fold more frequent and threefold larger in $N d n$-KO (1.90 \pm 0.27 vesicles/neuron; $3.06 \pm 0.81 \mu \mathrm{m}^{2} ; n=4$ neonates) than in WT cell cultures $\left(0.20 \pm 0.03\right.$ vesicles/neuron; $0.83 \pm 0.26 \mu \mathrm{m}^{2} ; n=4$ neonates $)$. We thus conclude that Necdin deficiency in mice alters the morphology of 5-HT fibers but not the number of 5-HT neurons.

\section{Discussion}

To secure life, the mammalian RRG must be able to elaborate its rhythmic command and to adequately adapt it to environmental and behavioral changes. At birth, the RRG ability to correctly function depends on maturational processes controlled by key genes affecting intrinsic rhythmogenic mechanisms (Blanchi et al., 2003) and the development of neurotransmitter systems, including the 5-HT system (Bou-Flores et al., 2000; Burnet et al., 2001; Gaspar et al., 2003; Viemari et al., 2004). Here, we report central sleep apneas in PWS from birth and similar apneas in $N d n$-KO. In mice, Necdin deficiency does not disable the RRG to function but alters its function, inducing apneas, rhythm irregularity, and misregulations, even when isolated in vitro. We show Necdin expression in 5-HT neurons of WT mice through embryogenesis and in adults. Although Necdin deficiency does not modify the number of 5-HT neurons, it alters the 5-HT metabolism and the 5-HT modulation of the RRG during the perinatal period and, permanently, the morphology and distribution of 5-HT vesicles. Subsequently, these 5-HT alterations may affect the maturation of the respiratory system and induce persisting breathing deficits in $\mathrm{Ndn}-\mathrm{KO}$, and probably in PWS.

\section{Apneas and blunted respiratory regulations in PWS patients and $\mathrm{Ndn}$-KO neonates}

Sleep apneas are common in PWS children and adults (Goldstone, 2004; Festen et al., 2006). We show that they exist as early as birth in PWS neonates and persist in PWS infants. Surviving $N d n$-KO mice, similar to PWS, have frequent apneas during quiet, probably sleeping periods, and irregular rhythm. Because these respiratory deficits exist in vitro, they are central from origin, although peripheral alterations cannot be excluded. In E18 embryos from a different Necdin-deficient strain, the respiratory rhythm is highly variable, with arrests lasting several tens of minutes in some preparations (Ren et al., 2003; Pagliardini et al., 2005). We never observed such long-lasting arrests in $\mathrm{Ndn}$-KO preparations, probably because embryos with such drastic deficits could not have survived until P2. We only studied the less affected mutants, those that could, similarly to PWS patients, survive.

$N d n-\mathrm{KO}$, as PWS patients, have blunted respiratory regulations. In responses to hypercapnia, $\mathrm{Ndn}$-KO mice increase their ventilation but less than WT mice. This regulation, which is crucial to secure $\mathrm{pH}$ homeostasis, involves neurons from the RVLM ventral surface that detect $\mathrm{CO}_{2} / \mathrm{pH}$ changes, and several neurotransmitter systems that adjust the chemosensitivity and the RRG responsiveness, including the 5 -HT system (Wang et al., 2002; Nattie et al., 2004; Richerson, 2004; Taylor et al., 2004). Ndn-KO also have blunted respiratory responses to hypoxia as shown herein. In vivo, a short-lasting hypoxia that activates carotid bodies chemoceptors and, in turn, the RRG increases ventilation in 

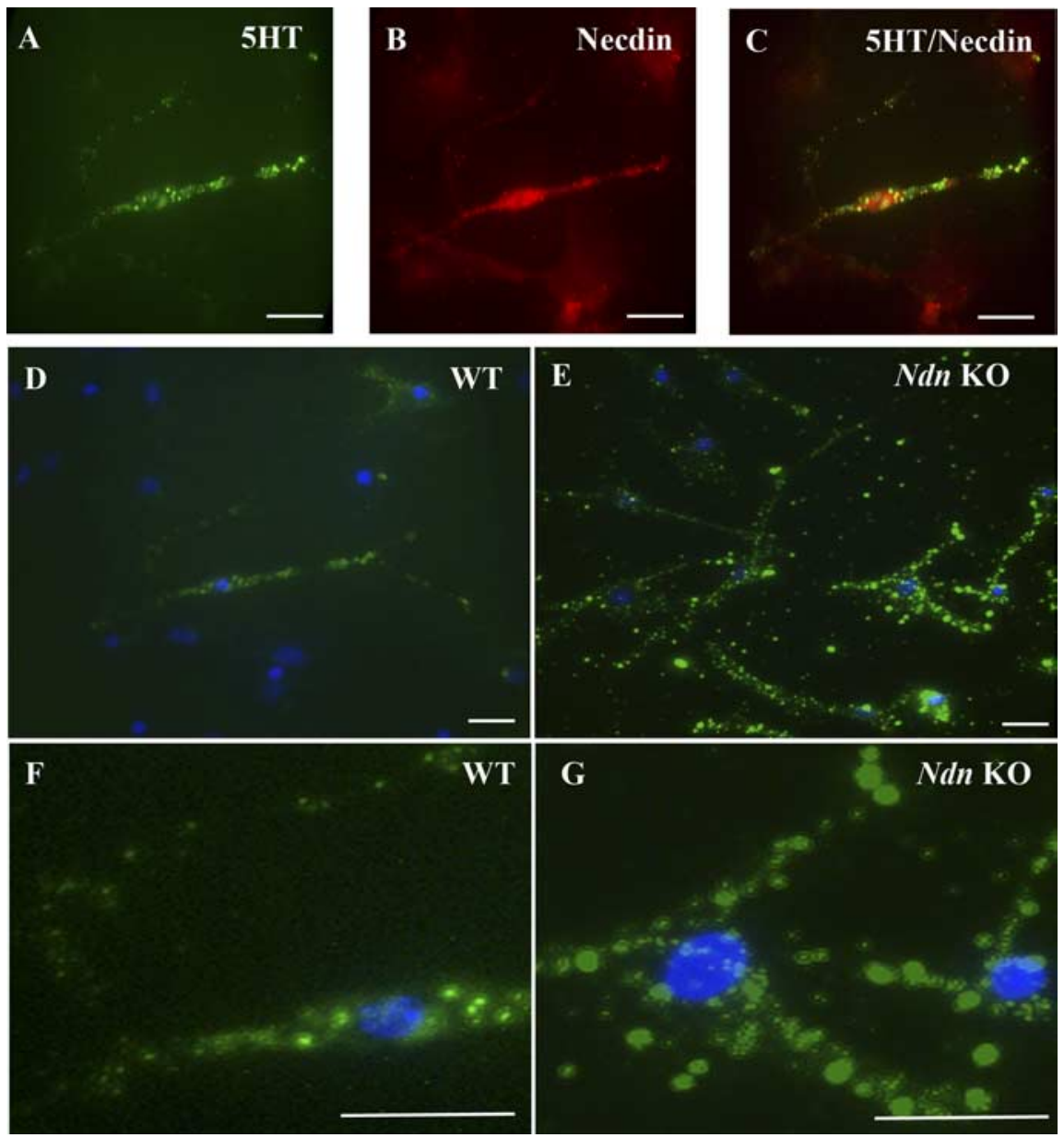

Figure 7. Morphological analysis of 5-HT vesicles in raphe primary cultures from WT and Ndn-KO neonates. $\boldsymbol{A}-\boldsymbol{C}$, Double immunostaining to label a 5-HT-positive (green, $\boldsymbol{A}$ ) and Necdin-positive (red, $\boldsymbol{B}$ ) neuron (merged labeling in $\boldsymbol{C}$ ). Necdin is expressed in vesicles present in cytoplasm and dendrites. D-G, 5-HT (green) immunoreactive neurons in raphe cultures from WT $(\boldsymbol{D}, \boldsymbol{F})$ and $N d n-K 0$ neonates $(\boldsymbol{E}, \boldsymbol{G})$. Enlargements showing detailed features of 5 -HT neurons $(\boldsymbol{F}, \boldsymbol{G})$. Note the presence of enlarged 5-HT vesicles in 5-HT neurons from Ndn-KO compared with WT. Scale bar, $10 \mu \mathrm{m}$.

WT and $N d n-\mathrm{KO}$ mice but less in $N d n$-KO mice. The weakness of the $N d n-\mathrm{KO}$ response may be peripheral in origin (carotid body chemosensitivity) and/or central. In vitro, mimicking central hypoxia by applying nonoxygenated aCSF depressed the RRG in WT and $N d n$-KO preparations, but less in $N d n$-KO and with a slower time course. Furthermore, an interaction between Necdin and HIF1 (hypoxia-inducible factor 1) has been reported (Moon et al., 2005), which reinforces the idea that Necdin participates in the response to hypoxia.

\section{Central respiratory deficits and 5-HT alterations}

In PWS, the 5-HT metabolism may be altered, because 5HIAA concentrations in the CSF (Akefeldt et al., 1998) and monoamine oxidase activity in platelets (Akefeldt and Mansson, 1998) are abnormal. Moreover, 5-HT affects RRG maturation and function. First, endogenous 5-HT facilitates the fetal and neonatal RRG via 5- $\mathrm{HT}_{1 \mathrm{~A}}-\mathrm{R}$ (Hilaire and Duron, 1999; Bou-Flores et al., 2000) and perinatal excess of 5-HT resulting from monoamine oxidase A (MAOA) deficiency induces an irregular rhythm and a loss of the 5- $\mathrm{HT}_{1 \mathrm{~A}}$ facilitation of RRG (Cases et al., 1995; Bou-Flores et al., 2000). Second, overactivation of 5-HT biosynthesis induces apneas in neonatal rats (Hilaire et al., 1993), and 5-HT participates in sleep apneas in adult mice (Popa et al., 2005). Third, 5-HT participates in respiratory responses to hypercapnia and hypoxia (Hilaire and Duron, 1999; Burnet et al., 2001; Wang et al., 2002; Nattie et al., 2004; Richerson, 2004; Taylor et al., 2004; Tryba et al., 2006). Thus, one might conceive that 5 -HT alterations in $\mathrm{Ndn}$-KO may induce irregular rhythm, apneas, and altered regulations. Nonetheless, rhythm alterations are less severe in $\mathrm{Ndn}$-KO than in MafB mutants where the pre-Bötzinger complex is altered (Blanchi et al., 2003). Effectively, the RRG of $\mathrm{Ndn}$-KO functions and may even produce a stable rhythm under 5-HT. The rodent RRG is located within the RVLM, where neurons of the pFRG and the pre-Bötzinger complex play key roles in rhythmogenesis (Smith et al., 1991; Rekling and Feldman, 1998; Gray et al., 2001; Manzke et al., 2003; Onimaru and Homma, 2003; Hayes and Del Negro, 2007). In the RVLM, Necdin transcript is detected, but very few or any neurons of the preBötzinger complex and pFRG areas, respectively, express Necdin protein, whereas all 5-HT neurons do. Thus, we propose a pivotal role for 5-HT alterations in $N d n-\mathrm{KO}$ breathing deficits: Necdin deficiency alters the 5-HT system, which in turn alters the prenatal 5-HT modulation of the RRG, affecting its maturation and its postnatal function. However, if $\mathrm{Ndn}$-KO breathing deficits originate, in part, from 5 -HT alterations that secondarily alter the RRG, we cannot exclude that other, not yet identified, alterations might also contribute to such breathing deficits, in particular a primary alteration of the RRG and/or the carotid bodies that could especially affect respiratory rhythm generation and regulations, respectively.

Breathing deficits persist in $N d n$-KO adults, although their excess of 5-HT becomes statistically insignificant. Similarly, breathing deficits persist in MAOA-KO adults, although their excess of 5-HT weakens with age (Cases et al., 1995; Burnet et al., 2001). Thus, in addition to perinatal excess of 5-HT, other factors could contribute to persisting breathing deficits. In MAOA-KO, an abnormal expression/function of $5-\mathrm{HT}_{1 \mathrm{~A}}-\mathrm{R}$ plays a key role, abolishing the $5-\mathrm{HT}_{1 \mathrm{~A}}$ facilitation of the RRG, altering its maturation and the wiring of the respiratory network (Bou-Flores et al., 2000). In $N d n$-KO, however, the RRG normally responds to activation of $5-\mathrm{HT}_{1 \mathrm{~A}}-\mathrm{R}$ with 8 -OHDPAT, suggesting a normal expression/function of $5-\mathrm{HT}_{1 \mathrm{~A}}-\mathrm{R}$. Because $5-\mathrm{HT}$ activates the RRG of neonatal rodents mainly via medullary $5-\mathrm{HT}_{1 \mathrm{~A}}-\mathrm{R}$ (Hilaire and Duron, 1999; Bou-Flores et al., 2000), the normal RRG response to specific $5-\mathrm{HT}_{1 \mathrm{~A}}-\mathrm{R}$ activation versus the abnormal response to $5-\mathrm{HT}$ in $\mathrm{Ndn}$-KO is puzzling. Several speculative, nonexclusive issues may be proposed to explain this discrepancy. First, a plethora of receptors mediate the 5-HT effects, and we have only tested the RRG response to the selective activation of a few of them (Gaspar et al., 2003; Manzke et al., 2003); one cannot exclude that some 5-HT receptor subtypes, not yet identified, have abnormal expression/function in $N d n-\mathrm{KO}$, acquiring a new 
role in RRG regulation. Second, because exogenous 5-HT application simultaneously activates all the different 5-HT receptors in different brainstem loci, the RRG response to this massive and synchronous activation may be different from the RRG response to the selective activation of individual 5-HT receptors, especially if the expression of a given $5-\mathrm{HT}$ receptor is altered in $\mathrm{Ndn}$ - $\mathrm{KO}$. Third, exogenous 5-HT application, in addition to its activation of 5-HT receptors, aggravates the excess of $5-\mathrm{HT}$ in $\mathrm{Ndn}-\mathrm{KO}$ medulla, and this may further affect the 5-HT metabolism, especially the processes implicated in 5-HT release and reuptake. Interestingly, we report a permanently altered morphology of 5-HT fibers in $\mathrm{Ndn}$-KO fetuses, neonates, and adults, with large, swollen 5-HT vesicles. This permanent 5-HT anomaly may contribute to both the altered RRG maturation and the persisting breathing deficits in adults. A better characterization of these abnormal vesicles and their physiopathological consequences are under study.

In $\mathrm{Ndn}$-KO, exogenous 5-HT decreases the PBF, abolishes the respiratory arrests, and stabilizes the RRG through unknown mechanisms. The 5-HT-induced restoration of a stable RRG activity in $\mathrm{Ndn}$-KO suggests that pharmacological treatments targeting the 5-HT system might soften their breathing deficits. In PWS, treatments with the selective 5-HT uptake inhibitor fluoxetine alleviates some specific symptoms (Dech and Budow, 1991; Warnock and Kestenbaum, 1992; Benjamin and Buot-Smith, 1993; Hellings and Warnock, 1994; Goldstone, 2004), but nothing has been reported on breathing symptoms. However, chronic treatments with fluoxetine increase the respiratory response to hypercapnia in rats (Taylor et al., 2004), and short-term fluoxetine treatment improves respiration of obese non-PWS patients suffering from apnea/hypopnea periods during sleep (Kopelman et al., 1992).

\section{Necdin function and the 5 -HT system}

Two cellular functions are reported for Necdin. First, Necdin acts as an anti-apoptotic factor (Andrieu et al., 2003). However, we counted a normal number of 5-HT neurons, catecholamine neurons, and hypoglossal motor neurons in $\mathrm{Ndn}$-KO. Second, Necdin affects neuronal migration, axonal extension, arborization, and fasciculation. Necdin deficiency has been reported to alter projections of 5-HT profiles toward rostral structures at E15.5 (Lee et al., 2005) and the RVLM at E18.5 (Lee et al., 2005; Pagliardini et al., 2005), and we show altered morphology of 5-HT vesicles in fibers innervating the medulla of $N d n$-KO embryos, neonates, and adults. Thus, Necdin deficiency induces developmental alterations that may affect several networks, including the maturing 5-HT network itself, which, subsequently, alters the prenatal maturation and postnatal function of the RRG.

\section{Is Necdin involved in non-PWS breathing deficit diseases?}

Using a PWS mouse model, we report that Necdin deficiency alters both 5-HT and respiratory systems. However, PWS is a multigenic disease, and patients are diagnosed on the presence of multiple symptoms; some of which could be attributed to genes other than NECDIN. Clearly, only NECDIN mutations have never been associated with patients diagnosed with PWS. We propose that such mutations might contribute to diseases accompanied with apneas and involving 5-HT alterations, such as sleep apneas syndrome (SAS) and sudden infant death syndrome (SIDS). SAS is the most common respiratory disease in adults; abnormally elevated 5HIIAA levels have been reported in SAS (Cramer et al., 1981), and 5-HT agents are thought to be potentially efficient (Veasey, 2003). SIDS is a multifactorial disease, involving both genetic and environmental factors; developmental abnormality in 5-HT and respiratory systems could play major roles in SIDS (Kinney et al., 2001; Paterson et al., 2006). SIDS is assumed to originate from fatal apneas during sleep, and there is an increased family history of SIDS in adults with SAS (Marcus, 2001). Thus, NECDIN might be a genetic factor contributing to apneas of PWS, SIDS, and SAS.

In conclusion, we suggest a causal relationship between Necdin deficiency, 5-HT dysfunction, altered RRG maturation, and persisting breathing deficits in $\mathrm{Ndn}$-KO mice but also in PWS and possibly in some non-PWS patients suffering from apneas and 5-HT system alterations.

\section{References}

Akefeldt A, Mansson JE (1998) Is monoamine oxidase activity elevated in Prader-Willi syndrome? Eur Child Adolesc Psychiatry 7:163-165.

Akefeldt A, Ekman R, Gillberg C, Mansson JE (1998) Cerebrospinal fluid monoamines in Prader-Willi syndrome. Biol Psychiatry 44:1321-1328.

Andrieu D, Watrin F, Niinobe M, Yoshikawa K, Muscatelli F, Fernandez PA (2003) Expression of the Prader-Willi gene Necdin during mouse nervous system development correlates with neuronal differentiation and p75NTR expression. Gene Expr Patterns 3:761-765.

Andrieu D, Meziane H, Marly F, Angelats C, Fernandez P-A, Muscatelli F (2006) Sensory defects in Necdin deficient mice result from a loss of sensory neurons correlated within an increase of developmental programmed cell death. BMC Dev Biol 6:56.

Benjamin E, Buot-Smith T (1993) Naltrexone and fluoxetine in PraderWilli syndrome. J Am Acad Child Adolesc Psychiatry 32:870-873.

Bevengut M, Coulon P, Hilaire G (2008) Brain nuclei controlling the spinal respiratory motoneurons in the newborn mouse. Adv Exp Med Biol 605:127-132.

Blanchi B, Kelly LM, Viemari JC, Lafon I, Burnet H, Bevengut M, Tillmanns S, Daniel L, Graf T, Hilaire G, Sieweke MH (2003) MafB deficiency causes defective respiratory rhythmogenesis and fatal central apnea at birth. Nat Neurosci 6:1091-1100.

Bou-Flores C, Lajard AM, Monteau R, De Maeyer E, Seif I, Lanoir J, Hilaire G (2000) Abnormal phrenic motoneuron activity and morphology in neonatal monoamine oxidase A-deficient transgenic mice: possible role of a serotonin excess. J Neurosci 20:4646-4656.

Brewer GJ (1995) Serum-free B27/neurobasal medium supports differentiated growth of neurons from the striatum, substantia nigra, septum, cerebral cortex, cerebellum, and dentate gyrus. J Neurosci Res 42:674-683.

Burnet H, Bevengut M, Chakri F, Bou-Flores C, Coulon P, Gaytan S, Pasaro R, Hilaire G (2001) Altered respiratory activity and respiratory regulations in adult monoamine oxidase A-deficient mice. J Neurosci 21:5212-5221.

Cases O, Seif I, Grimsby J, Gaspar P, Chen K, Pournin S, Muller U, Aguet M, Babinet C, Shih JC, De Maeyer E (1995) Aggressive behavior and altered amounts of brain serotonin and norepinephrine in mice lacking MAOA. Science 268:1763-1766.

Cramer H, Warter JM, Renaud B, Krieger J, Marescaux CH, Hammers R (1981) Cerebrospinal fluid adenosine 3',5'-monophosphate, 5-hydroxyindoleacetic acid and homovanillic acid in patients with sleep apnoea syndrome. J Neurol Neurosurg Psychiatry 44:1165-1167.

Dech B, Budow L (1991) The use of fluoxetine in an adolescent with PraderWilli syndrome. J Am Acad Child Adolesc Psychiatry 30:298-302.

Festen DA, de Weerd AW, van den Bossche RA, Joosten K, Hoeve H, HokkenKoelega AC (2006) Sleep-related breathing disorders in prepubertal children with Prader-Willi syndrome and effects of growth hormone treatment. J Clin Endocrinol Metab 91:4911-4915.

Gaspar P, Cases O, Maroteaux L (2003) The developmental role of serotonin: news from mouse molecular genetics. Nat Rev Neurosci 4:1002-1012.

Gaytan SP, Pasaro R, Coulon P, Bevengut M, Hilaire G (2002) Identification of central nervous system neurons innervating the respiratory muscles of the mouse: a transneuronal tracing study. Brain Res Bull 57:335-339.

Gerard M, Hernandez L, Wevrick R, Stewart CL (1999) Disruption of the mouse necdin gene results in early post-natal lethality. Nat Genet 23:199-202.

Goldstone AP (2004) Prader-Willi syndrome: advances in genetics, pathophysiology and treatment. Trends Endocrinol Metab 15:12-20. 
Gray PA, Janczewski WA, Mellen N, McCrimmon DR, Feldman JL (2001) Normal breathing requires preBotzinger complex neurokinin-1 receptorexpressing neurons. Nat Neurosci 4:927-930.

Hayes JA, Del Negro CA (2007) Neurokinin receptor-expressing preBotzinger complex neurons in neonatal mice studied in vitro. J Neurophysiol 97:4215-4224.

Hellings JA, Warnock JK (1994) Self-injurious behavior and serotonin in Prader-Willi syndrome. Psychopharmacol Bull 30:245-250.

Hilaire G (2006) Endogenous noradrenaline affects the maturation and function of the respiratory network: possible implication for SIDS. Auton Neurosci 126- 127:320-331.

Hilaire G, Duron B (1999) Maturation of the mammalian respiratory system. Physiol Rev 79:325-360.

Hilaire G, Morin D, Lajard AM, Monteau R (1993) Changes in serotonin metabolism may elicit obstructive apnoea in the newborn rat. J Physiol (Lond) 466:367-381.

Hilaire G, Viemari JC, Coulon P, Simonneau M, Bevengut M (2004) Modulation of the respiratory rhythm generator by the pontine noradrenergic A5 and A6 groups in rodents. Respir Physiol Neurobiol 143:187-197.

Jay P, Rougeulle C, Massacrier A, Moncla A, Mattei MG, Malzac P, Roeckel N, Taviaux S, Lefranc JL, Cau P, Berta P, Lalande M, Muscatelli F (1997) The human necdin gene, NDN, is maternally imprinted and located in the Prader-Willi syndrome chromosomal region. Nat Genet 17:357-361.

Kinney HC, Filiano JJ, White WF (2001) Medullary serotonergic network deficiency in the sudden infant death syndrome: review of a 15-year study of a single dataset. J Neuropathol Exp Neurol 60:228-247.

Kopelman PG, Elliott MW, Simonds A, Cramer D, Ward S, Wedzicha JA (1992) Short-term use of fluoxetine in asymptomatic obese subjects with sleep-related hypoventilation. Int J Obes Relat Metab Disord 16:825-830.

Lautenschlager M, Holtje M, von Jagow B, Veh RW, Harms C, Bergk A, Dirnagl U, Ahnert-Hilger G, Hortnagl H (2000) Serotonin uptake and release mechanisms in developing cultures of rat embryonic raphe neurons: age- and region-specific differences. Neuroscience 99:519-527.

Lee S, Walker CL, Karten B, Kuny SL, Tennese AA, O’Neill MA, Wevrick R (2005) Essential role for the Prader-Willi syndrome protein necdin in axonal outgrowth. Hum Mol Genet 14:627-637.

Manzke T, Guenther U, Ponimaskin EG, Haller M, Dutschmann M, Schwarzacher S, Richter DW (2003) 5-HT4(a) receptors avert opioid-induced breathing depression without loss of analgesia. Science 301:226-229.

Marcus CL (2001) Sleep-disordered breathing in children. Am J Respir Crit Care Med 164:16-30.

Moon HE, Ahn MY, Park JA, Min KJ, Kwon YW, Kim KW (2005) Negative regulation of hypoxia inducible factor-1alpha by necdin. FEBS Lett 579:3797-3801.

Morcuende S, Delgado-Garcia J-M, Ugolini G (2002) Neuronal premotor networks involved in eyelid responses: retrograde transneuronal tracing with Rabies virus from the orbicularis oculi muscle in the rat. J Neurosci 22:8808-8818.

Muscatelli F, Abrous DN, Massacrier A, Boccaccio I, Le Moal M, Cau P, Cremer H (2000) Disruption of the mouse Necdin gene results in hypothalamic and behavioral alterations reminiscent of the human PraderWilli syndrome. Hum Mol Genet 9:3101-3110.

Nagai T, Obata K, Tonoki H, Temma S, Murakami N, Katada Y, Yoshino A, Sakazume S, Takahashi E, Sakuta R, Niikawa N (2005) Cause of sudden, unexpected death of Prader-Willi syndrome patients with or without growth hormone treatment. Am J Med Genet A 136:45-48.

Nattie EE, Li A, Richerson G, Lappi DA (2004) Medullary serotonergic neurones and adjacent neurones that express neurokinin-1 receptors are both involved in chemoreception in vivo. J Physiol (Lond) 556:235-253.
Nixon GM, Brouillette RT (2002) Sleep and breathing in Prader-Willi syndrome. Pediatr Pulmonol 34:209-217.

Onimaru H, Homma I (2003) A novel functional neuron group for respiratory rhythm generation in the ventral medulla. J Neurosci 23:1478-1486,

Pagliardini S, Ren J, Wevrick R, Greer JJ (2005) Developmental abnormalities of neuronal structure and function in prenatal mice lacking the Prader-Willi syndrome gene necdin. Am J Pathol 167:175-191.

Paterson DS, Trachtenberg FL, Thompson EG, Belliveau RA, Beggs AH, Darnall R, Chadwick AE, Krous HF, Kinney HC (2006) Multiple serotonergic brainstem abnormalities in sudden infant death syndrome. JAMA 296:2124-2132.

Popa D, Lena C, Fabre V, Prenat C, Gingrich J, Escourrou P, Hamon M, Adrien J (2005) Contribution of 5- $\mathrm{HT}_{2}$ receptor subtypes to sleepwakefulness and respiratory control, and functional adaptations in knock-out mice lacking 5- $\mathrm{HT}_{2 \mathrm{~A}}$ receptors. J Neurosci 25:11231-11238.

Rekling JC, Feldman JL (1998) PreBotzinger complex and pacemaker neurons: hypothesized site and kernel for respiratory rhythm generation. Annu Rev Physiol 60:385-405.

Ren J, Lee S, Pagliardini S, Gerard M, Stewart CL, Greer JJ, Wevrick R (2003) Absence of Ndn, encoding the Prader-Willi syndrome-deleted gene necdin, results in congenital deficiency of central respiratory drive in neonatal mice. J Neurosci 23:1569-1573.

Richerson GB (2004) Serotonergic neurons as carbon dioxide sensors that maintain pH homeostasis. Nat Rev Neurosci 5:449-461.

Schrander-Stumpel CT, Curfs LM, Sastrowijoto P, Cassidy SB, Schrander JJ, Fryns JP (2004) Prader-Willi syndrome: causes of death in an international series of 27 cases. Am J Med Genet A 124:333-338.

Smith JC, Ellenberger HH, Ballanyi K, Richter DW, Feldman JL (1991) PreBotzinger complex: a brainstem region that may generate respiratory rhythm in mammals. Science 254:726-729.

Taylor NC, Li A, Green A, Kinney HC, Nattie EE (2004) Chronic fluoxetine microdialysis into the medullary raphe nuclei of the rat, but not systemic administration, increases the ventilatory response to CO2. J Appl Physiol 97:1763-1773.

Tryba AK, Pena F, Ramirez JM (2006) Gasping activity in vitro: a rhythm dependent on 5- $\mathrm{HT}_{2 \mathrm{~A}}$ receptors. J Neurosci 26:2623-2634.

Uliel S, Tauman R, Greenfeld M, Sivan Y (2004) Normal polysomnographic respiratory values in children and adolescents. Chest 125:872-878

Veasey SC (2003) Serotonin agonists and antagonists in obstructive sleep apnea: therapeutic potential. Am J Respir Med 2:21-29.

Viemari JC, Bevengut M, Burnet H, Coulon P, Pequignot JM, Tiveron MC, Hilaire G (2004) Phox2a gene, A6 neurons, and noradrenaline are essential for development of normal respiratory rhythm in mice. J Neurosci 24:928-937.

Viemari JC, Roux JC, Tryba AK, Saywell V, Burnet H, Pena F, Zanella S, Bevengut M, Barthelemy-Requin M, Herzing LB, Moncla A, Mancini J Ramirez JM, Villard L, Hilaire G (2005) Mecp2 deficiency disrupts norepinephrine and respiratory systems in mice. J Neurosci 25:11521-11530.

Wang W, Bradley SR, Richerson GB (2002) Quantification of the response of rat medullary raphe neurones to independent changes in $\mathrm{pH}(\mathrm{o})$ and $\mathrm{P}(\mathrm{CO} 2)$. J Physiol (Lond) 540:951-970.

Warnock JK, Kestenbaum T (1992) Pharmacologic treatment of severe skin-picking behaviors in Prader-Willi syndrome. Two case reports. Arch Dermatol 128:1623-1625.

Zanella S, Roux JC, Viemari JC, Hilaire G (2006) Possible modulation of the mouse respiratory rhythm generator by $\mathrm{A} 1 / \mathrm{C} 1$ neurones. Respir Physiol Neurobiol 153:126-138.

Zanella S, Viemari JC, Hilaire G (2007) Muscarinic receptors and alpha2adrenoceptors interact to modulate the respiratory rhythm in mouse neonates. Respir Physiol Neurobiol 157:215-225. 